Sevillano Rodríguez, M. E. (2020): "Zonificación de la amenaza ante inundaciones a partir de un método de evaluación multicriterio en la ciudad de Santiago de Cali, Colombia”, GeoFocus, $n^{\circ}$ 25, p. 47-76. http://dx.doi.org/10.21138/GF.661

\title{
ZONIFICACIÓN DE LA AMENAZA ANTE INUNDACIONES A PARTIR DE UN MÉTODO DE EVALUACIÓN MULTICRITERIO EN LA CIUDAD DE SANTIAGO DE CALI, COLOMBIA
}

\author{
MARÍA EUGENIA SEVILLANO RODRÍGUEZ \\ Universidad Autónoma de Ciudad Juárez \\ Avenida Hermanos Escobar, CP. 32410 Juárez, México \\ ${ }^{1}$ mariasevillano14@ hotmail.com
}

\section{RESUMEN}

El propósito de este artículo es zonificar la amenaza por inundación en Santiago de Cali, Colombia, a partir de un método de evaluación multicriterio integrado por siete variables de análisis, construido a partir de la combinación lineal ponderada e implementado en la plataforma de un sistema de información geográfica. Los resultados muestran que la amenaza clasificada como alta, ocupa $6 \%$ de la superficie inundable, la media $22 \%$ y la baja $72 \%$. Las áreas más vulnerables son sectores ubicados en 37 barrios localizados principalmente en la zona oriental de la ciudad, condición que está determinada por la profundidad de inundación, la acumulación de flujo, la inclinación de la pendiente y la cercanía a canales y fuentes hídricas. La zonificación de la amenaza ante inundaciones es un acercamiento al conocimiento del riesgo de desastre y se aproxima a la instrumentación del ordenamiento del territorio.

Palabras clave: amenaza; evaluación multicriterio; inundación urbana.

\section{ZONING OF THE THREAT TO FLOODS FROM A MULTICRITERIA EVALUATION METHOD IN THE CITY OF SANTIAGO DE CALI, COLOMBIA}

\section{ABSTRACT}

The purpose of this article is to Zone the flood threat in Santiago de Cali, Colombia, based on a multicriteria evaluation method integrated by seven analysis variables, constructed from the linear combination weighted and implemented in the platform of a geographic information system. The results shows that the threat classified as high, occupies $6 \%$ of the surface of the floodplate, the average $22 \%$ and the low $72 \%$. The most vulnerable areas are sectors located in 37 neighborhoods located mainly in the eastern part of the city, a condition that is determined by the depth of flood, the accumulation of flow, the slope and the proximity to channels and 


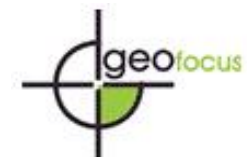

Revista Internacional de Ciencia y Tecnología de la Información Geográfica International Review of Geographical Information Science and Technology

Sevillano Rodríguez, M. E. (2020): "Zonificación de la amenaza ante inundaciones a partir de un método de evaluación multicriterio en la ciudad de Santiago de Cali, Colombia", GeoFocus, $n^{\circ}$ 25, p. 47-76. http://dx.doi.org/10.21138/GF.661

water sources. The zoning of the threat to floods is an approach to the knowledge of disaster risk and approaches the instrumentation of land management.

Keywords: threat; multicriteria evaluation; urban flood

\section{Introducción}

América Latina es una región amenazada constantemente por fenómenos naturales extremos, configurando situaciones que han llegado a retrasar procesos de desarrollo. Así ha quedado demostrado en la experiencia de algunos países donde la incorporación de criterios de reducción de riesgo de desastre en el ordenamiento territorial presenta obstáculos por los vacíos en el conocimiento de amenazas, vulnerabilidades, riesgos y su aplicación para derivar decisiones de carácter regulatorio que permitan mejorar las condiciones de vida de los habitantes (RubianoVargas \& Ramírez-Cortés, 2009). Asimismo, los instrumentos normativos referidos al riesgo y a la planificación urbana son dirigidos por diversas instancias provocando conflictos entre distintos niveles de gobierno (Wong, 2010). Para la Cooperación Técnica Alemana (GTZ) (2010), la subregión Andina (Colombia, Ecuador, Perú, Venezuela) ha demostrado el deseo de avanzar en enfoques de ordenamiento descentralizados, siendo favorable incorporar el riesgo para identificarlo y reducirlo por lo que se deben fortalecer a las entidades nacionales en su función de orientación y facilitación de los procesos de planificación del territorio.

En el caso de Colombia los avances en el ordenamiento territorial han sido importantes, pero no han logrado los impactos deseados y la gestión del riesgo no es fácil por los retos que conlleva generar estrategias de ordenamiento (Banco Mundial \& GFDRR, 2012). Así por ejemplo, durante el periodo 1914-2018 se reportaron en Colombia 16855 inundaciones causando la muerte a 2030 personas y la destrucción de 89689 viviendas (DESINVENTAR, 2019). Las amenazas de origen hidrometereológico representan uno de los mayores peligros que enfrenta la población debido a que ocasionan cuantiosas pérdidas humanas y materiales (CEPAL \& BID, 2012). La amenaza es el fenómeno peligroso con capacidad de desestabilizar un ecosistema o los elementos que los componen (CEPAL, 2002). La exposición permanente a inundaciones y la necesidad de reducir los daños ocasionados, ha permitido realizar investigaciones aplicadas para evaluar la amenaza por inundación.

En estas evaluaciones se tienen distintos marcos de referencia para la aplicación metodológica: métodos históricos (Gobierno de España-Ministerio de Medio Ambiente \& Medio Rural Marino, 2011; Pérez-Morales, 2012; Rodríguez-Gaviria, 2016), métodos geomorfológicos (Benito, 2007, Rodríguez-Gaviria, 2016) métodos hidrológicos e hidráulicos (Materón et al., 2006, Pérez-Morales, 2012; Cartaya \& Mantuano-Duarte, 2016) y los métodos asistidos por percepción remota (Belmonte \& Caamaño, 2009; Delgado \& Quintero, 2013; Lorenzo \& Hernández, 2018, Anusha \& Bharathi, 2019; Li et al., 2019; Macchione et al., 2019). Todos parten de enfoques distintos, pero coinciden en que el peligro de inundación debe reconocerse a partir de parámetros físicos y geográficos. Ahora bien, identificar la amenaza ante un evento de inundación representa un insumo básico para el conocimiento de riesgo (Perles-Roselló et al., 2018). 


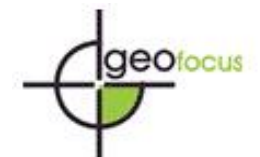

Revista Internacional de Ciencia y Tecnología de la Información Geográfica International Review of Geographical Information Science and Technology

Sevillano Rodríguez, M. E. (2020): "Zonificación de la amenaza ante inundaciones a partir de un método de evaluación multicriterio en la ciudad de Santiago de Cali, Colombia", GeoFocus, n ${ }^{\circ}$ 25, p. 47-76. http://dx.doi.org/10.21138/GF.661

Sin embargo, zonificar la condición de peligro resulta mucho más valioso para fines de ordenamiento territorial, debido a que la zonificación clasifica el área de inundación en niveles de amenaza a partir del análisis conjunto de criterios que deben ser valorados en cada caso particular (República de Colombia-IDEAM, 2017). En relación con esto, Barrantes-Castillo \& VargasBogantes (2011) zonificaron la amenaza por inundación y la categorizaron como una herramienta para reducir los desastres causados a asentamientos humanos altamente vulnerables.

Las zonificaciones de amenaza o peligrosidad son relevantes para mitigar afectaciones de carácter estructural y ante inundaciones, sin ser el único procedimiento que debe ser llevado a cabo para la gestión de desastres. Al igual que los estudios de peligrosidad, los métodos de evaluación de vulnerabilidad y riesgo de inundación han evolucionado, asumiendo una perspectiva integradora para reconocer la importancia de la ocupación del territorio y el desarrollo de actividades humanas, asegurando que las condiciones de vulnerabilidad social deben ser estudiadas con la misma rigurosidad que se hace con la manifestación del peligro (Wilchex-Chaux, 1993; Blaikie et al., 1996; Cardona, 2001; Cutter et al.,2003; Camarasa-Belmonte et al.,2008; Ley \& Calderón, 2008; Díez-Herrero et al., 2009; Perles-Roselló, 2010; Pérez- Morales et al., 2016; Perles-Roselló et al., 2017). Igualmente, los trabajos sobre políticas, ordenamiento territorial y riesgo han avanzado, transcendiendo las medidas estructurales de reducción para dar importancia a la planificación del territorio, la comunicación comunitaria y la educación (Ollero-Ojeda, 2015).

Según Olcina-Cantos (2008), se han dado cambios importantes en la concepción de riesgos naturales amparados en directrices y normativas que apoyan la incorporación de estudios de riesgo en la planificación territorial, resultando medidas de mitigación sostenibles en un marco de cambio climático. Este hecho marca diferencias entre la gestión de inundación mediante la construcción de obras hidráulicas y la reducción del problema a partir de modelos adecuados de uso de suelo (Perles-Roselló et al., 2018). En el caso de Colombia, la normativa con incidencia territorial que previene el riesgo se fundamenta en la Ley 388 de 1997 (República de Colombia, 1997). En esta norma, se estableció que los planes de ordenamiento territorial deben delimitar zonas de riesgo y determinar las acciones para prevenir afectaciones a causa de estos fenómenos. En el mismo sentido, la Ley Orgánica de Ordenamiento Territorial (LOOT) (República de Colombia, 2011), dicta medidas para la organización político-administrativa del territorio colombiano (integración del ordenamiento territorial y el ordenamiento ambiental).

La LOOT, favoreció la estructuración del Sistema Nacional de Gestión de Riesgo de Desastres (SNGRD) con la intención de fomentar el conocimiento, reducción y el manejo de emergencias, transfiriendo la autonomía del nivel nacional hacia departamentos municipios y asociaciones (Calderón-Ramírez \& Frey, 2017). La Ley 1523 de 2012 (República de Colombia, 2012), crea el SNGRD y dicta otras disposiciones como incorporar en los planes de ordenamiento territorial las consideraciones sobre desarrollo seguro y sostenible derivadas de la gestión del riesgo. La relación que existe entre la normatividad y la organización del espacio, se respalda a partir de la misma ley en la cual se plantea la utilización del suelo en correspondencia a la protección del medio ambiente y la prevención de los desastres. Es decir, la función pública del urbanismo debería tener como objetivo mejorar la seguridad de los asentamientos humanos ante riesgos naturales y determinar zonas no urbanizables que presenten riesgos para la localización de estructuras habitacionales. 


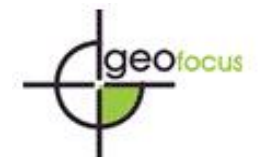

Revista Internacional de Ciencia y Tecnología de la Información Geográfica International Review of Geographical Information Science and Technology

Sevillano Rodríguez, M. E. (2020): "Zonificación de la amenaza ante inundaciones a partir de un método de evaluación multicriterio en la ciudad de Santiago de Cali, Colombia", GeoFocus, $n^{\circ}$ 25, p. 47-76. http://dx.doi.org/10.21138/GF.661

Las ausencias visibles en la aplicación de los instrumentos de ordenamiento territorial en el país, apuntan a la falta de estudios de amenazas, vulnerabilidades y riesgos a escala local o a los vacíos presentes en términos metodológicos y teóricos en las investigaciones que existen (Ramírez \& Rubiano, 2009). En consecuencia, debe retomarse desde la realidad urbana investigaciones para el conocimiento oportuno del riesgo que aporten al diagnóstico territorial (Massiris, 2005), teniendo en cuenta los regímenes jurídicos del país. En suma, los enfoques de estudios de riesgo han abordado la peligrosidad para identificar los factores físicos que generan las inundaciones (Cartaya \& Mantuano-Duarte, 2016) además, de investigaciones de vulnerabilidad y riesgo en las cuales la amenaza resulta ser un componente más del análisis, cobrando importancia la construcción social, en la que la estructuración humana determina la magnitud de daños que puede ocasionar una inundación (Wilchex-Chaux, 1993; Cardona, 2001; Camarasa-Belmonte et al., 2008). A estos se adhieren los análisis de riesgo orientados a la política y la ordenación del territorio con acciones sostenibles alineadas desde la planificación que requieren la implementación de estrategias de seguimiento y control (Ramírez \& Rubiano, 2009; Perles-Roselló et al., 2018).

Conviene subrayar, que los estudios de amenaza siguen vigentes y son necesarios en el proceso de conocimiento de riesgo dado que, a partir de estos puede representarse la manifestación natural del peligro. En otras palabras, corresponden a la identificación del área inundable y su zonificación. Sin embargo, no es la única condición relevante debido a que en una situación de desastre por inundación las afectaciones a personas y recursos materiales dependerán de las condiciones sociales, la distribución espacial de los habitantes y los elementos del lugar. De ahí que las ciencias sociales, sean indispensables en los análisis de vulnerabilidad y riesgo. Estas dos condiciones (amenaza y vulnerabilidad), enriquecen los análisis y enfoques y apuntan a soluciones más eficaces y sostenibles territorialmente (Perles-Roselló et al., 2018). Todo esto parece confirmar la importancia de la cartografía del riesgo para mostrar los impactos potenciales que se pueden producir en bienes, personas y actividades (Masgrau, 2004). La elaboración de mapas ha mejorado con los avances en sistemas de información geográfica y la incorporación de métodos de análisis, aportando desde la cartografía de peligrosidad hasta la de vulnerabilidad y riesgo (Olcina-Cantos \& Díez-Herrero, 2017).

Habría que decir también, que los sistemas de información geográfica han demostrado ser eficientes para apoyar distintas temáticas que apuntan al ordenamiento del territorio y al riesgo de desastres. En este caso, la complementariedad entre la técnica y el método de evaluación multicriterio (EMC) responden a la necesidad de zonificar la amenaza por inundación en Cali, Colombia. Por su parte, la EMC admite una estimación cuantitativa de criterios que permiten adaptar los resultados a una prospectiva territorial con el fin de propiciar una ocupación del suelo coincidente con sus oportunidades y limitantes (Barredo-Cano, 1996). En cuanto a la aplicación del método, Chávez-Cortés et al. (2017), evaluaron la susceptibilidad a inundaciones a partir de un índice de vulnerabilidad biofísica utilizando criterios ponderados que se implementaron en un sistema de información geográfica resultando la clasificación del área inundada. Es relevante reconocer en este sentido, la importancia de la utilización de técnicas semi-automatizadas que se aproximen a condiciones reales de ocupación del territorio a favor de ciudades más seguras y menos vulnerables ante eventos de desastres. 


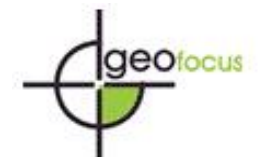

Revista Internacional de Ciencia y Tecnología de la Información Geográfica International Review of Geographical Information Science and Technology

Sevillano Rodríguez, M. E. (2020): "Zonificación de la amenaza ante inundaciones a partir de un método de evaluación multicriterio en la ciudad de Santiago de Cali, Colombia", GeoFocus, n ${ }^{\circ}$ 25, p. 47-76. http://dx.doi.org/10.21138/GF.661

El propósito de este artículo es zonificar la amenaza ante inundación en Santiago de Cali, Colombia. Para la obtención de resultados se siguió un método de EMC, en relación con siete variables de análisis integradas por: La profundidad de inundación, acumulación de flujo, canales, ríos, pendientes, humedales y quebradas. Desde esta perspectiva se presenta, el estado de la cuestión, los métodos, la valoración de hallazgos, la discusión y finalmente las conclusiones.

\section{Estado de la cuestión}

Actualmente los análisis de riesgo de desastres plantean la necesidad de realizar deducciones integrales que den cuenta de condiciones de amenaza y vulnerabilidad. En esta concepción, la construcción social del riesgo es relevante, entendiendo que un evento físico puede causar daños cuando los elementos socioeconómicos son expuestos en condiciones de fragilidad en áreas de potencial afectación y/o nuevos eventos físicos son generados por intervención humana (Narváez et al., 2009; Díez et al., 2009). Los estudios integrales del riesgo nos indican que no puede existir amenaza sin vulnerabilidad y viceversa, resultando indispensable conocer cómo se manifiestan estos fenómenos en el territorio. Así las cosas, la gestión del riesgo de desastre se convierte en un proceso complejo sistemático integrado por decisiones, acciones y actividades orientadas a reducir vulnerabilidades sociales, cuya intención principal sea la deconstrucción del riesgo (Alcántara-Ayala et al., 2019).

Se debe agregar que la concepción de un enfoque de riesgos basado en procesos, también integra a investigaciones aplicadas a estudios de caso, entendiendo que el primer paso para reducir los daños es conocer la manera en que se manifiesta el fenómeno. En este orden, consideramos que el momento inicial para determinar la situación de riesgo debe enmarcarse en la identificación del fenómeno amenazante y zonificarlo. Seguidamente, examinar la vulnerabilidad y riesgo, para posteriormente formular y aplicar elementos de mitigación y estrategias de atención a emergencias orientadas a partir de la planificación y el ordenamiento territorial. El tener claridad sobre el estado que presentan estos escenarios de riesgo (amenaza-vulnerabilidad), lleva a la utilización de diversas metodologías que, en principio dependen del fenómeno amenazante (inundación, movimiento en masa, incendios forestales, terremotos etc.), la intención del investigador y la normativa del país para orientar los estudios y la entrega de resultados.

En términos reales, los métodos usados para identificar la amenaza son tradicionales, de carácter técnico y ampliamente reconocidos desde las ciencias analíticas o positivistas (RubianoMartínez, 2010). Esto no significa que su aplicación sea sencilla, ya que requieren de un exhaustivo desarrollo metodológico. Para identificar la amenaza o el peligro por inundación existen varios métodos, entre los más implementados: El histórico, geomorfológico, hidrológico e hidráulico y los asistidos por percepción remota. Entre los trabajos que abordan estos enfoques se encuentran Rodríguez-Gaviria (2016), con la utilización de datos históricos aportados por comunidades para reconocer zonas afectadas por inundaciones en el municipio de Caucasia, Colombia; Soria-Díaz et al. (2015), con la identificación de unidades de peligro a partir de datos geomorfológicos en la ciudad de Iquitos Perú; Materón et al. (2006), con el uso de métodos hidrológicos en el estudio de inundabilidad en la urbanización de río Nima en Palmira, Colombia; Lorenzo \& Hernández (2018), con la obtención de cartografía de áreas inundadas utilizando imágenes de radar TanDEM-X en Acapulco de Juárez, Guerrero-México. 


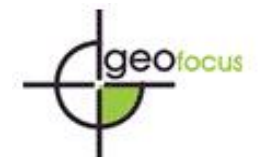

Revista Internacional de Ciencia y Tecnología de la Información Geográfica International Review of Geographical Information Science and Technology

Sevillano Rodríguez, M. E. (2020): "Zonificación de la amenaza ante inundaciones a partir de un método de evaluación multicriterio en la ciudad de Santiago de Cali, Colombia", GeoFocus, $n^{\circ}$ 25, p. 47-76. http://dx.doi.org/10.21138/GF.661

Otro rasgo importante de la concepción de la amenaza es su zonificación, la cual es empleada mayormente en el ordenamiento territorial y reglamentada bajo la normativa vigente de cada país cuando la intención es orientar procesos de desarrollo y planificación (República de Colombia-IDEAM, 2017). En este abordaje, la cartografía de riesgos se ha trasformado en una obligación legal con el manejo de conceptos, métodos y herramientas que aportan a los procesos de planificación territorial y a sus instrumentos (Planes de Ordenamiento Territorial, Planes de Gestión de Riesgo de Desastres) (Olcina-Cantos \& Díez-Herrero, 2017). Por consiguiente, la utilización de sistemas de información geográfica ha apoyado el análisis de la distribución espacial de amenazas riesgos y vulnerabilidades, admitiendo la integración de datos.

En relación con esto, la EMC es uno de los métodos que permite distintas fuentes de datos y se desarrolló inicialmente en la década de 1970 por Thomas L. Saaty, siendo ampliamente aplicado para resolver problemas prácticos en economía, transporte, educación, asignación de recursos, planificación y gestión integrada, su abundante utilización se debe a la incorporación de criterios que pueden basarse en información cuantitativa o cualitativa (Dang, Babel \& Huynh, 2011). Satty (1980), diseño el proceso jerárquico para resolver problemas que integran criterios múltiples. De acuerdo a Barredo (1996), este modelo trata de evaluar un conjunto de alternativas que desde el punto de vista geográfico corresponden a porciones del territorio con características ambientales, sociales o económicas. Los parámetros propuestos por Saaty hacen posible un conjunto de investigaciones que desde todos los ámbitos han aportado al conocimiento. Entre las investigaciones que han empleado un conjunto de variables basado en un EMC para la zonificación de inundaciones se encuentran trabajos en muchas partes del mundo.

González-Valencia (2006) propusieron la metodológica para el análisis de inundaciones y movimientos en masa en el Valle de Aburrá, Colombia; Gao et al. (2007) realizaron la evaluación de vulnerabilidad a partir de un análisis jerárquico con aplicación en la región del lago Dongting en China; Meyer et al. (2008) lo utilizan para estimar criterios de riesgo económico, social y ambiental para el río Mulde en Sajonia, Alemania. También Shever et al. (2011) emplearon multicriterio para integrar dimensiones ambientales y sociales que estudian el riesgo por inundación en Alemania; Yahaya et al. (2010) establecieron criterios para determinar áreas vulnerables a inundaciones en la cuenca del río Hadejia-Jama'are, Nigeria; Olivera-Acosta et al. (2011) usaron EMC en la determinación de escenarios de peligro a inundaciones en la cuenca Guanabo en Cuba; Dang et al. (2011) aplicaron parámetros de riesgo por inundación en el área del río Day en Vietnam; SánchezRomán (2012) y Sánchez \& Martínez-González (2014) reportaron inundaciones pluviales en una cuenca urbana aplicando el método de ponderación mixta en Coro, Venezuela; Mendoza-Mejía et al. (2014) ocuparon factores físico-naturales para examinar la vulnerabilidad biofísica en Toluca, México.

Asimismo, Siddayao et al. (2014) incorporaron la jerarquía analítica para la evaluación de riesgos de llanuras de inundación en el municipio de Enrile en la provincia de Cagayan, norte de Filipinas; Abdalla-Elsheikh et al. (2015) realizaron un mapa de riesgo de inundación basado en SIG y técnicas multicriterio en Terengganu Malasia; Chávez-Cortés et al. (2017) evaluaron la vulnerabilidad biofísica ante inundaciones en Atoyac-Oaxaca de Juárez, México; Rimba et al. (2017), aplicaron la técnica en el mapeo de inundación en Okazaki Japón; Shivaprasad-Sharma et al. (2018) clasificaron el riesgo de inundación mediante criterios múltiples en la cuenca del río Kopili, Assam, India; 


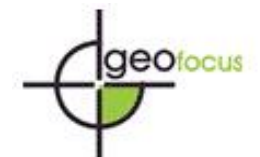

Revista Internacional de Ciencia y Tecnología de la Información Geográfica

International Review of Geographical Information Science and Technology

Sevillano Rodríguez, M. E. (2020): "Zonificación de la amenaza ante inundaciones a partir de un método de evaluación multicriterio en la ciudad de Santiago de Cali, Colombia", GeoFocus, $n^{\circ}$ 25, p. 47-76. http://dx.doi.org/10.21138/GF.661

Shale-Ogato et al. (2020) se apoyaron en un sistema de información geográfica (SIG) y el método de análisis multicriterio para determinar el peligro de inundación y riesgo en Oromia, Etiopía.

La EMC, es un método que permite la utilización de variables de diferente procedencia, esto da oportunidad al investigador para seleccionar los criterios más pertinentes, de mayor confiabilidad y más accesibles (en el caso que la información básica deba ser solicitada a entidades de gobierno). De igual modo, los sistemas de información geográfica se han convertido en una técnica fundamental para fortalecer la cartografía de riesgo y los procesos de planificación y ordenamiento territorial (Perles-Roselló et al., 2017; Olcina-Cantos et al., 2017).

\section{Materiales, datos y métodos}

La realización del proceso parte del método de Evaluación Multicriterio (EMC) con la combinación lineal ponderada. El proceso se aplicó para zonificar áreas de inundación urbana en Santiago de Cali, Colombia. En el apartado se describe la zona de estudio, los materiales, las técnicas de análisis, el procesamiento de la información y la integración del modelo final.

\subsection{Zona de estudio}

Santiago de Cali, se encuentra ubicada en la parte sur occidental de Colombia dentro de lo que se ha llamado graben del Cauca, es la tercera ciudad más poblada del país y la capital del departamento del Valle del Cauca. Tiene una población municipal de 2227642 habitantes, de los cuales 2172527 residen en el área urbana (República de Colombia - DANE, 2018). El aspecto geomorfológico y geológico de la ciudad está determinado por una franja montañosa localizada en la parte occidental y el valle aluvial del río Cauca en la línea oriental, integrado por depósitos de origen aluvial que han propiciado la construcción de viviendas (Jiménez, 2005). Hacen parte del sistema hídrico los ríos Meléndez, Lili, Cali, Aguacatal, Pance y Cañaveralejo que atraviesan la ciudad para alimentar la corriente principal del Cauca, a esto se suman 48 humedades siendo los más importantes las lagunas Charco Azul y el Pondaje (Alcaldía de Santiago de Cali-DAGMA, 2010; Alcaldía Municipal de Santiago de Cali, 2014). La zona urbana se compone de 22 comunas, 337 barrios (unidades más pequeñas de planificación) y el área de expansión (Ver Figura 1).

La expansión física de Cali se ha dado hacia la zona montañosa y en el valle aluvial del río Cauca, sectores ocupados informalmente en sus inicios (Jiménez, 2005). De esta manera, los desastres se intensificaron debido a la exposición y vulnerabilidad social de los habitantes. Uno de los problemas más graves se originó en los años ochenta con el crecimiento natural sin planeación del distrito de Agua Blanca (al oriente de la ciudad), donde los nuevos habitantes construían sus viviendas encima de rellenos artesanales para favorecerse de inundaciones futuras (por ser terrenos bajos presentan altos niveles freáticos) (Alcaldía Municipal de Santiago de Cali, 2014; Sevillano Rodríguez; Bravo Peña, 2018). Las inundaciones en Cali se han hecho presentes de forma fluvial, por el desbordamiento de los ríos y pluvial a causa de la insuficiencia de canales de lluvias que atraviesan varios sectores de la ciudad. De acuerdo a la Alcaldía Municipal de Santiago de Cali (2014), desde 1970, se han producido inundaciones en todos los años (excepto en 1991, año de escasez de lluvias). De ahí que, durante el período 1986-2018 se reportaran 766 inundaciones en 186 barrios de la ciudad (DESINVENTAR, 2018; República de Colombia-UNGRD, 2018; Sevillano-Rodríguez et al., 2020). 


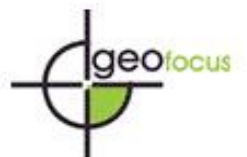

Sevillano Rodríguez, M. E. (2020): "Zonificación de la amenaza ante inundaciones a partir de un método de evaluación multicriterio en la ciudad de Santiago de Cali, Colombia", GeoFocus, no 25, p. 47-76. http://dx.doi.org/10.21138/GF.661
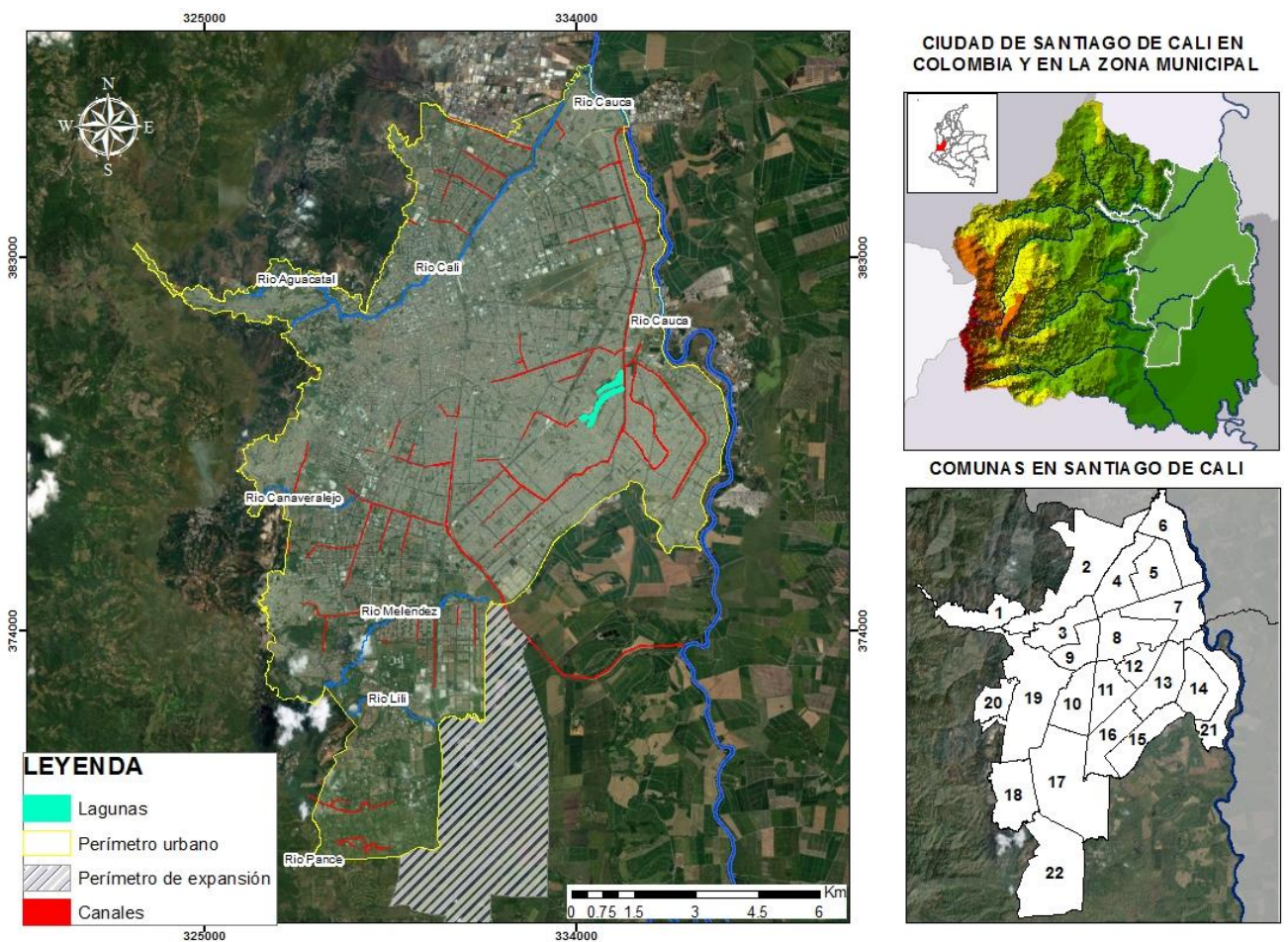

Figura 1: Ubicación de la ciudad de Santiago de Cali, Colombia

Fuente: Elaboración propia con base en datos de Alcaldía Municipal de Santiago de Cali, 2014

Entidades de gobierno han adelantado esfuerzos en la generación de cartografía de amenaza. En el año 2012 se realizó una modelación de peligro a inundaciones a partir de información del río Cauca y tributarios (Alcaldía Municipal de Santiago de Cali, 2014). En 2013, el diagnóstico para el jarillón de Aguablanca en el cual se incorporó la simulación hidrológica e hidrodinámica del río Cauca para periodos de retorno de 100, 250 y 500 años, tomando como punto de calibración la estación Juanchito. En el procedimiento se calcularon cuatro parámetros: Área, profundidad, volumen y duración de la inundación, los resultados en un escenario de 500 años sería la permanencia de la inundación por 8,6 días, generando profundidades que oscilan entre $7 \mathrm{~cm}$ y más de 30 metros (Corporación OSSO y Royal HaskoningDHV, 2013).

El análisis en el diagnóstico, indica que el hacer caso omiso a las adecuaciones en el sistema de drenaje seguirá ocasionando inundaciones en barrios donde históricamente se han presentado. Otros aportes se han hecho a partir de estudios hidráulicos en los ríos Aguacatal, Meléndez, Lili, y Cañaveralejo a su paso por el área urbana de Santiago de Cali (Alcaldía municipal de Santiago de Cali - DAGMA, 2011). Actualmente, la ciudad cuenta con un Plan Municipal de Gestión de Riesgo de Desastres (PMGRD), en el cual se priorizó el escenario de inundación y se determinaron algunos elementos programáticos de articulación a la planificación del territorio (Alcaldía Municipal de Santiago de Cali-PMGRD, 2018). 


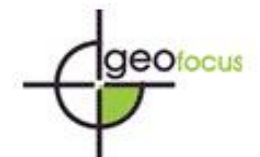

Revista Internacional de Ciencia y Tecnología de la Información Geográfica International Review of Geographical Information Science and Technology

Sevillano Rodríguez, M. E. (2020): "Zonificación de la amenaza ante inundaciones a partir de un método de evaluación multicriterio en la ciudad de Santiago de Cali, Colombia", GeoFocus, $n^{\circ}$ 25, p. 47-76. http://dx.doi.org/10.21138/GF.661

Para cumplir con el objetivo de este trabajo se desarrolló un procedimiento metodológico que consiste en reconocer características generales de la zona a estudiar y dar explicación al modelo seguido para la obtención de resultados.

\subsection{Materiales}

Para el desarrollo del trabajo se tomó como referencia investigaciones previas que emplearon variables de análisis que coinciden con el tema: Profundidad (Díez-Herrero et al., 2009; Dang et al., 2011; Sánchez-Román, 2012; Sánchez \& Martínez-González, 2014; Martínez-González \& Castrillón- Cruz, 2014; Rodríguez-Gaviria, 2016), acumulación de flujo (Olivera-Acosta, et al., 2011), cercanía a canales (República de Colombia-Decreto 2811, 1974; República de ColombiaDecreto 2245, 2017), cercanía a ríos (González-Valencia, 2006; Siddayao et al., 2014; ChávezCortés et al., 2017), pendientes (González-Valencia, 2006; Uribe-Alcántara et al., 2010; RodríguezGaviria, 2016; Chávez-Cortés et al., 2017; Rimba et al., 2017; Shale-Ogato et al., 2020), humedales (República de Colombia-Decreto 2811, 1974; González-Valencia, 2006; Siddayao et al., 2014; Chávez-Cortés et al., 2017; República de Colombia- Decreto 2245, 2017), quebradas (República de Colombia-Decreto 2811, 1974; González-Valencia, 2006; Chávez-Cortés et al., 2017). Así, se conformó la base de datos integrada por: El área de inundación de la ciudad, un modelo digital de elevaciones (DEM), la profundidad de inundación, la acumulación de flujo, canales de agua, ríos, pendientes, humedales, quebradas, comunas y barrios. Dicha información deriva del gobierno municipal (Alcaldía Municipal de Santiago de Cali - IDESC, 2014) y del procesamiento digital de imágenes de radar provenientes del portal de la NASA (NASA, 2018; Sevillano-Rodríguez et al., 2020).

- Área de Inundación: Información en formato ráster, obtenida mediante técnicas de teledetección realizadas por el autor a partir de imágenes Sentinel 1, suministradas por el portal de la NASA (NASA, 2018; Sevillano-Rodríguez et al., 2020).

- Modelo Digital de Elevaciones (MDE). Información de tipo ráster que representa la distribución espacial de la altitud de la superficie del terreno, consiste en un archivo tipo ráster que contiene una matriz de celdas cuadradas con la elevación en cada una de ellas con una resolución espacial de 10 metros, obtenida del portal de la NASA (NASA, 2018).

- Profundidad de la inundación. Información de tipo ráster, obtenida a partir de procesamiento del autor, resultado de la interacción entre el modelo digital de elevaciones y la zona inundable.

- Acumulación de flujo. Información de tipo ráster, obtenida a partir de procesamiento del autor.

- Canales. Archivo tipo vectorial obtenida a partir de la administración municipal de Santiago de Cali (Alcaldía Municipal de Santiago de Cali - IDESC, 2014)

- Ríos. Archivo tipo vectorial obtenida a partir de la administración municipal de Santiago de Cali (Alcaldía Municipal de Santiago de Cali - IDESC, 2014)

- Pendientes. Archivo tipo vectorial obtenida a partir de la administración municipal de Santiago de Cali (Alcaldía Municipal de Santiago de Cali - IDESC, 2014)

- Humedales. Archivo tipo vectorial obtenida a partir de la administración municipal de Santiago de Cali (Alcaldía Municipal de Santiago de Cali - IDESC, 2014) 


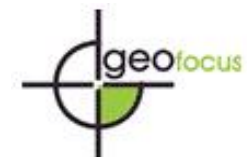

Revista Internacional de Ciencia y Tecnología de la Información Geográfica International Review of Geographical Information Science and Technology

Sevillano Rodríguez, M. E. (2020): "Zonificación de la amenaza ante inundaciones a partir de un método de evaluación multicriterio en la ciudad de Santiago de Cali, Colombia", GeoFocus, $n^{\circ}$ 25, p. 47-76. http://dx.doi.org/10.21138/GF.661

- Quebradas. Archivo tipo vectorial obtenida a partir de la administración municipal de Santiago de Cali (Alcaldía Municipal de Santiago de Cali - IDESC, 2014)

- Comunas. Archivo tipo vectorial (Alcaldía Municipal de Santiago de Cali - IDESC, 2014)

- Barrios. Archivo tipo vectorial (Alcaldía Municipal de Santiago de Cali - IDESC, 2014)

\subsection{Técnicas de análisis.}

El método de análisis corresponde a la evaluación multicriterio (EMC), la cual se define como un conjunto de técnicas orientadas a asistir en la toma de decisiones, basando la interpretación en la utilización de diversas variables que pueden asistir en procesos de decisión (Barredo-Cano, 1996). Está metodología ha sido utilizada para dar solución a problemas de distinta índole por tanto existen diferentes alternativas. En este caso se utilizó la combinación lineal ponderada donde cada una de las cartografías parciales se estandarizó en un rango común para ser integrada por medio de una ponderación jerárquica (Barredo-Cano, 1996). Por consiguiente, nuestro objetivo es generar la zonificación de amenaza por inundación en la ciudad de Cali para reconocer los sectores que podrían afectarse mayormente ante la presencia del fenómeno.

\subsection{Procesamiento de la información}

El software utilizado es el sistema de información geográfica ArcMap, donde se desarrolló el procesamiento de los datos adquiridos que consistió en la homogenización de la base dentro del sistema de coordenadas correspondiente a Colombia - MAGNA_Cali_Valle_del_Cauca_2009. De acuerdo a la Tabla 2, la base de datos fue procesada para obtener la información específica de cada uno de los criterios. La estructura metodológica se compone inicialmente de la elaboración de las variables profundidad y acumulación de flujo. A continuación, se desarrolló el criterio de accesibilidad para las categorías: Canales, ríos, humedales y quebradas (República de ColombiaDecreto 2811, 1974; República de Colombia- Decreto 2245, 2017). Seguidamente, se integró la base de datos. En la Tabla 2, se crearon parámetros de reclasificación y se generó en la Tabla 3, la matriz de ponderación (jerarquía) para cada una de las variables. Finalmente, se determinó la amenaza alta, media y baja por inundación en la ciudad de Santiago de Cali, Colombia.

\section{A) Variables de análisis}

La variable profundidad, se obtuvo a partir del modelo digital de elevaciones y el área de inundación. Inicialmente se realizó un pre - procesamiento al Modelo Digital de Elevaciones (MDE) para lo cual se utilizó el comando Fill. Con esta herramienta se rellenaron las imperfecciones existentes en la superficie del MDE, de tal forma que las celdas en depresión alcanzaron el nivel del terreno de alrededor (Soza-Zamora, 2018). Posteriormente, fue procesada el área de inundación para obtener la altura promedio. La zona inundable, presentaba 106 polígonos que se convirtieron a vistas de línea para aplicar individualmente un Random con longitud de 100, como se muestra en la Figura 2 (Chuvieco, 2008). 


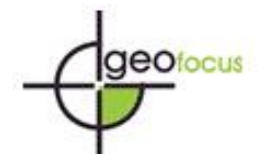

Sevillano Rodríguez, M. E. (2020): "Zonificación de la amenaza ante inundaciones a partir de un método de evaluación multicriterio en la ciudad de Santiago de Cali, Colombia", GeoFocus, $n^{\circ}$ 25, p. 47-76. http://dx.doi.org/10.21138/GF.661
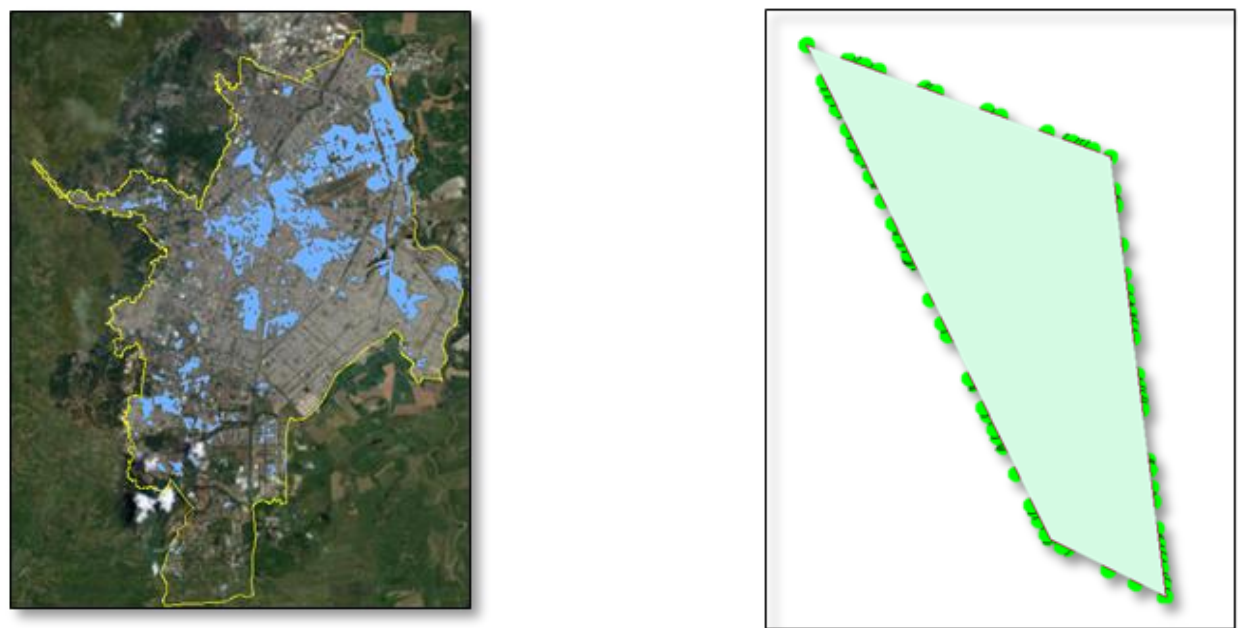

Figura 2: Random por cada polígono

Fuente: Elaboración propia

Al obtener los 100 puntos para cada polígono se comprobó la altura promedio utilizando el MDE articulado con la herramienta Extract value to point, en la Tabla 1 se verificó el promedio.

Tabla 1: Extracción de promedios de altura para cada polígono

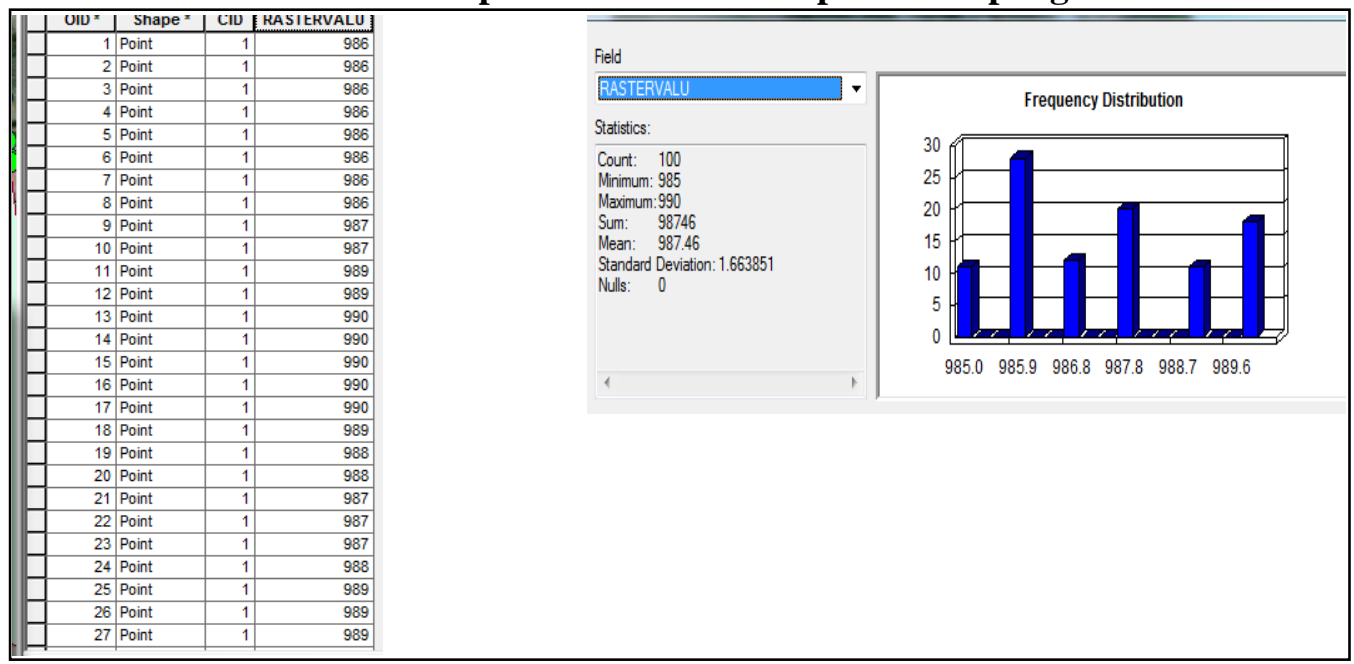

Fuente: Elaboración propia

Al terminar el mismo procedimiento para los 106 polígonos del área de inundación, se consiguió la altura promedio por separado (para cada polígono de inundación). Así, los resultados son convertidos a ráster, la profundidad para la fecha del evento de inundación se calculó con álgebra de mapas mediante la siguiente fórmula: 
Sevillano Rodríguez, M. E. (2020): "Zonificación de la amenaza ante inundaciones a partir de un método de evaluación multicriterio en la ciudad de Santiago de Cali, Colombia", GeoFocus, $n^{\circ}$ 25, p. 47-76. http://dx.doi.org/10.21138/GF.661

\section{Profundidad de inundación = Altura promedio - Modelo Digital de Elevaciones}

Variable acumulación de flujo. Se realizó la operación para determinar la dirección y acumulación de flujo utilizando las interfaces Flow direction - Flow acumulation. Con el ráster de acumulación de flujo, se determinó el número de celdas aguas arriba que vierten sobre cada una de las celdas inmediatamente aguas abajo de ella.

Variables de accesibilidad: Canales, ríos, humedales y quebradas. Se desarrolló el algoritmo de distancia euclidiana para las categorías: Canales, ríos, humedales y quebradas. La herramienta describe la relación de cada celda con un origen o un conjunto de orígenes basándose en la distancia de la línea recta, se calculó desde el centro de la celda hasta el centro de cada una de las celdas circundantes, generando un ráster de salida con una resolución espacial de 10 metros con la finalidad de hacer coincidir con la resolución del MDE. Esta distancia es segmentada en metros considerando la normativa de Colombia relacionada con las rondas de fuentes hídricas (República de Colombia-Decreto 2811, 1974; República de Colombia- Decreto 2245, 2017).

Variable Pendientes. La información de pendientes aporta información sobre la altura en distintos puntos de la ciudad, en relación con la inundación a menor altura mayor afectación por la ocurrencia del evento y viceversa (Valencia, 2006). La mayoría de variables fueron reclasificadas por Cortes Naturales (Jenks) (García de León \& Humacata, 2019). Tal como se establece en la Tabla 2.

Tabla 2: Parámetros de reclasificación

\begin{tabular}{|c|c|c|c|c|}
\hline Indicador & Parámetro de medida & Alto & Medio & Bajo \\
\hline Profundidad & $\begin{array}{l}\text { Profundidad } \\
\text { promedio }(\mathrm{cm})\end{array}$ & 10,1 a más de 30 & 5.1 a 10 & $\begin{array}{l}\text { Menos } 286 \\
\text { a } 5\end{array}$ \\
\hline Acumulación de flujo & $\begin{array}{l}\text { Acumulación de flujo en } \\
\text { cada celda } \\
\text { (\# de celdas que vierten) }\end{array}$ & 10,1 a más de 30 & 5.1 a 10 & 0 a 5 \\
\hline Canales & Distancia (m) & de 30 a 60 & $\begin{array}{l}60.1 \\
\text { a } 90\end{array}$ & $\begin{array}{l}\text { de } 90.1 \\
\text { a más de } 120\end{array}$ \\
\hline Ríos & Distancia (m) & de 30 a 60 & $\begin{array}{l}60.1 \\
a 90\end{array}$ & $\begin{array}{l}\text { de } 90.1 \\
\text { a más de } 120\end{array}$ \\
\hline Pendientes & Porcentaje & 0 a $7 \%$ & $\begin{array}{l}7.1 \\
\text { a } 14 \%\end{array}$ & 14.1 a mayor $70 \%$ \\
\hline Humedales & Distancia (m) & de 30 a 60 & $\begin{array}{l}60.1 \\
\text { a } 90\end{array}$ & $\begin{array}{l}90.1 \\
\text { a más de } 120\end{array}$ \\
\hline Quebradas & Distancia (m) & de 30 a 60 & $\begin{array}{l}60.1 \\
\text { a } 90\end{array}$ & $\begin{array}{l}90.1 \\
\text { a más de } 120\end{array}$ \\
\hline
\end{tabular}

Fuente: Elaboración propia 
Sevillano Rodríguez, M. E. (2020): "Zonificación de la amenaza ante inundaciones a partir de un método de evaluación multicriterio en la ciudad de Santiago de Cali, Colombia", GeoFocus, $n^{\circ}$ 25, p. 47-76. http://dx.doi.org/10.21138/GF.661

Después de haber determinado la reclasificación para las 7 variables de análisis, se estableció la ponderación jerárquica para cada una, tal como se muestra en la Tabla 3. Esto se realizó mediante la comparación por pares utilizando como apoyo la consulta a expertos para determinar la importancia de cada uno de los factores sobre los demás, estableciendo un peso a cada una de las variables (Barredo-Cano, 1996). En la matriz de comparación se puede verificar que la profundidad de inundación es la que tiene mayor valor con un $0.30 \%$, seguidamente los canales con un $0.22 \%$ y ríos con un $0.17 \%$. Mientras que la acumulación de flujo, las pendientes y los humedales obtienen cada una $0.2 \%$. En el caso de las quebradas se obtuvo un valor de $0.04 \%$ siendo esta variable la de menor importancia

Tabla 3: Matriz de comparación

\begin{tabular}{|c|c|c|c|c|c|c|c|c|c|}
\hline 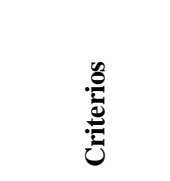 & 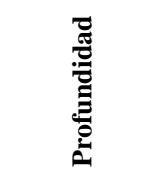 & 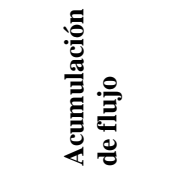 & 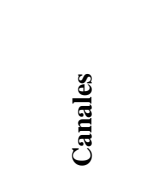 & 气气 & 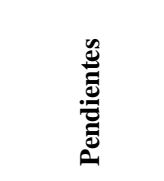 & 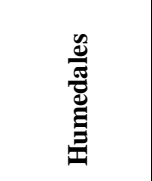 & 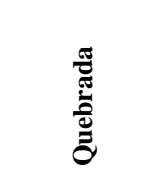 & है & 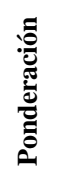 \\
\hline Profundidad & Profundidad & Profundidad & Profundidad & Profundidad & Profundidad & Profundidad & Profundidad & 7 & 0.30 \\
\hline $\begin{array}{l}\text { Acumulación } \\
\text { de flujo }\end{array}$ & & Acumulación & Canales & Ríos & Acumulación & Humedales & Quebradas & 2 & 0.09 \\
\hline Canales & & & Canales & Canales & Canales & Canales & Canales & 5 & 0.22 \\
\hline Ríos & & & & Ríos & Ríos & Ríos & Ríos & 4 & 0.17 \\
\hline Pendientes & & & & & Pendientes & Humedales & Pendiente & 2 & 0.09 \\
\hline Humedales & & & & & & Humedales & Humedales & 2 & 0.09 \\
\hline Quebradas & & & & & & & Quebradas & 1 & 0.04 \\
\hline & & & & & & & & 23 & 1.00 \\
\hline
\end{tabular}

Fuente: Elaboración propia

\subsection{Integración del modelo}

Establecidas las ponderaciones de cada variable, se procedió a la integración dentro de un modelo único por medio de la Suma Lineal Ponderada, la cual consiste en sumar cada criterio multiplicado por su peso (Barredo-Cano, 1996), quedando definido como: 
Sevillano Rodríguez, M. E. (2020): "Zonificación de la amenaza ante inundaciones a partir de un método de evaluación multicriterio en la ciudad de Santiago de Cali, Colombia", GeoFocus, no 25, p. 47-76. http://dx.doi.org/10.21138/GF.661

$$
R i=\sum_{j=1}^{n} W j X i j
$$

\section{Combinación Lineal Ponderada}

Ri: Aptitud del pixel i para la actividad evaluada.

Wj: Peso del criterio j.

Xij: Valor de la alternativa en el pixel i para el criterio j.

En este caso, la combinación lineal ponderada responde a:

$$
R i=\begin{aligned}
& \text { Profundidad } *(0.30)+\text { Acumulación } *(0.09)+\text { Canales }^{*}(0.22)+\text { Ríos }^{*}(0.17)+\text { Pendientes } \\
& *(0.09)+\text { Humedales } *(0.09)+\text { Quebradas } *(0.04)
\end{aligned}
$$

\section{Descripción y análisis de resultados}

Los sistemas de información geográfica se han convertido en una técnica importante para comprender aspectos relacionados con el territorio. Uno de los usos frecuentes de los SIG y la EMC es la evaluación de la aptitud para albergar determinados usos de suelo, o bien, evaluar la amenaza y vulnerabilidad a sufrir un evento catastrófico, riesgo de inundaciones, riesgo de contaminación ambiental, entre otros (Da Silva \& Cardozo, 2015). Conviene subrayar en este caso, la importancia de la aplicación del método en la obtención de resultados. A continuación, se presenta la condición de inundación analizando cada una de las variables de donde resulta la integración del modelo final.

\subsection{Reclasificación de modelos por variables de análisis}

Como primer criterio se tiene la profundidad de inundación en la Figura 3, generada a partir del área inundable y el MDE, posteriormente reclasificada. Demuestra que las áreas donde se generan mayores alturas de inundación se ubican en el sector oriental y al occidente, en la zona de confluencia de los ríos Aguacatal y Cali. 


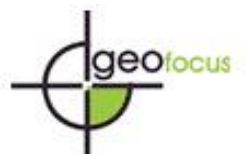

Sevillano Rodríguez, M. E. (2020): "Zonificación de la amenaza ante inundaciones a partir de un método de evaluación multicriterio en la ciudad de Santiago de Cali, Colombia", GeoFocus, $n^{\circ}$ 25, p. 47-76. http://dx.doi.org/10.21138/GF.661

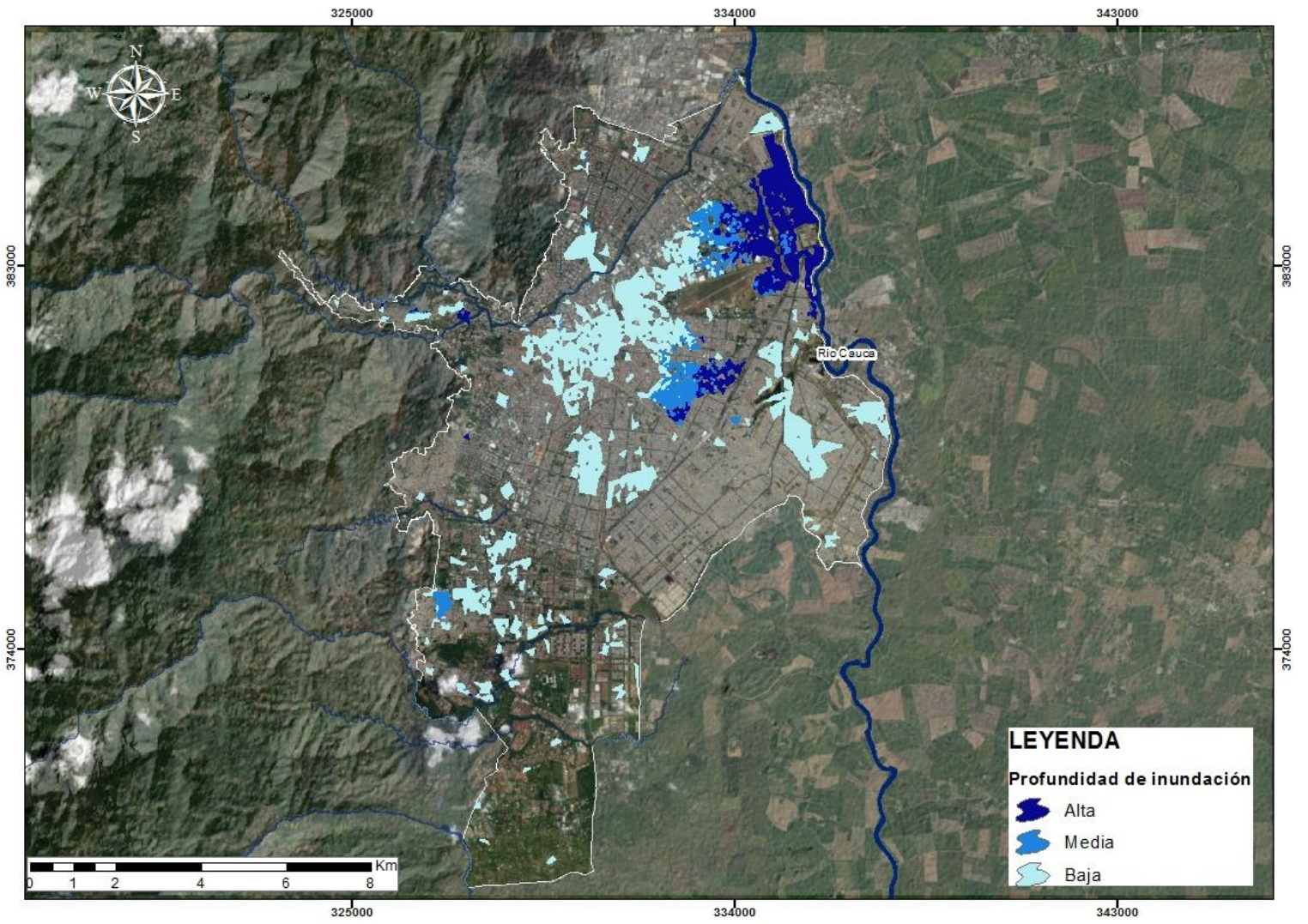

Figura 3: Profundidad de inundación

Fuente: Elaboración propia

En cuanto a la variable acumulación de flujo creada a partir de las interfaces Flow direction - Flow acumulatión. Indica que el mayor número de celdas de aguas arriba que vierten sobre cada una de las celdas inmediatamente aguas abajo en la Figura 4 (A), se ubican en diferentes puntos del área de inundación. En la Figura 4 (B), se muestra los puntos de los canales que presentan desbordamientos debido a su cercanía con la zona inundable, la cual se encuentra a menos de 60 metros (República de Colombia-Decreto 2811, 1974; República de Colombia- Decreto 2245, 2017). Cabe decir, que en la ciudad existe un sistema de canales, siendo los principales recolectores y los más importantes el Oriental y el Interceptor Sur, ambos convergen en el río Cauca. Estos conductos, se han desbordado en varias ocasiones (Jiménez, 2005). 


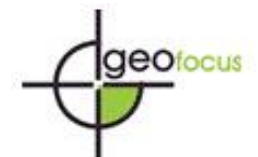

Sevillano Rodríguez, M. E. (2020): "Zonificación de la amenaza ante inundaciones a partir de un método de evaluación multicriterio en la ciudad de Santiago de Cali, Colombia", GeoFocus, n ${ }^{\circ}$ 25, p. 47-76. http://dx.doi.org/10.21138/GF.661
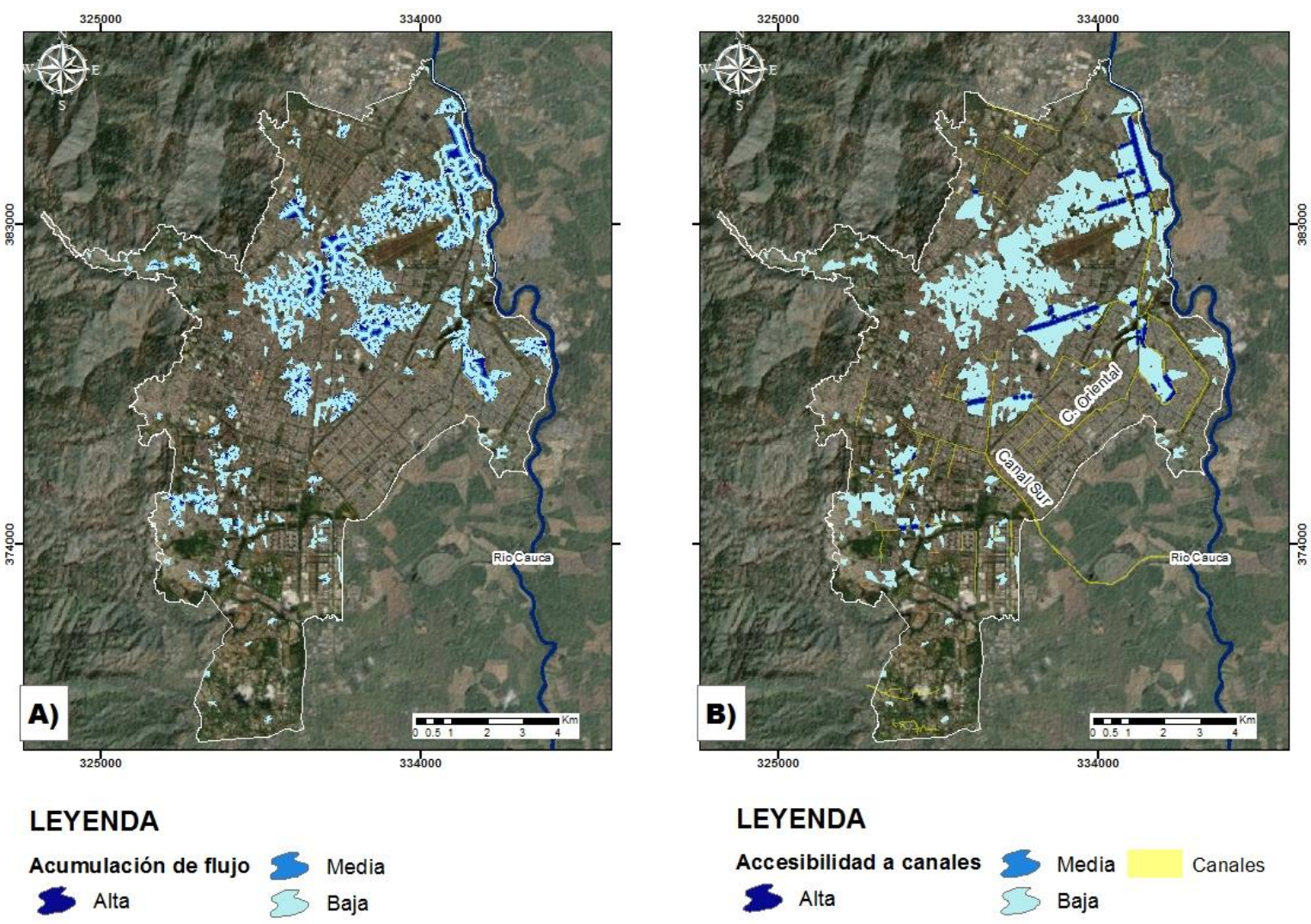

Figura 4: Acumulación de flujo y accesibilidad a canales

Fuente: Elaboración propia

De acuerdo a la Alcaldía Municipal de Santiago de Cali (2014), las principales fuentes hídricas del municipio y que además hacen parte de la dinámica urbana corresponden a los ríos: Aguacatal, Cali, Meléndez, Cañaveralejo, Lili, Pance y Cauca. A partir de la condición hídrica se han realizado estudios que han determinado puntos de inundación del río Cauca (Corporación OSSO y Royal HaskoningDHV, 2013), además de identificar el peligro por el desbordamiento de otras vertientes (Alcaldía Municipal de Santiago de Cali, 2014). En la Figura $5(A)$, los ríos que se salen de su cauce debido a su cercanía con la zona inundable (0 y 60 metros). Estas fuentes hídricas corresponden a los ríos Cali (barrios San Vicente, el Peñón, Santa Rita y Santa Teresita), Meléndez (barrios Unicentro, Mayapan las Vegas y Sect Meléndez) y Cauca en el barrio Puerto Nuevo.

Con respecto a las pendientes, Santiago de Cali se divide en dos áreas: la primera, localizada en la parte occidental donde se ubica la franja montañosa; la segunda en la línea oriental que corresponde al valle aluvial del rio Cauca (República de Colombia - INGEOMINAS-DAGMA, 2005). En la Figura $5(B)$, las pendientes con menor porcentaje se ubican en su mayoría en la parte oriental. Las áreas más inundables están asociadas con las llanuras y planicies. Es decir, el relieve suave y poco accidentado beneficia la recolección de agua, lo que aumenta la posibilidad de inundar amplias zonas (Dewan, 2013). 


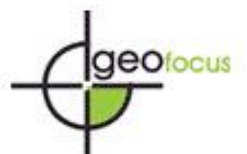

Sevillano Rodríguez, M. E. (2020): "Zonificación de la amenaza ante inundaciones a partir de un método de evaluación multicriterio en la ciudad de Santiago de Cali, Colombia", GeoFocus, no 25, p. 47-76. http://dx.doi.org/10.21138/GF.661

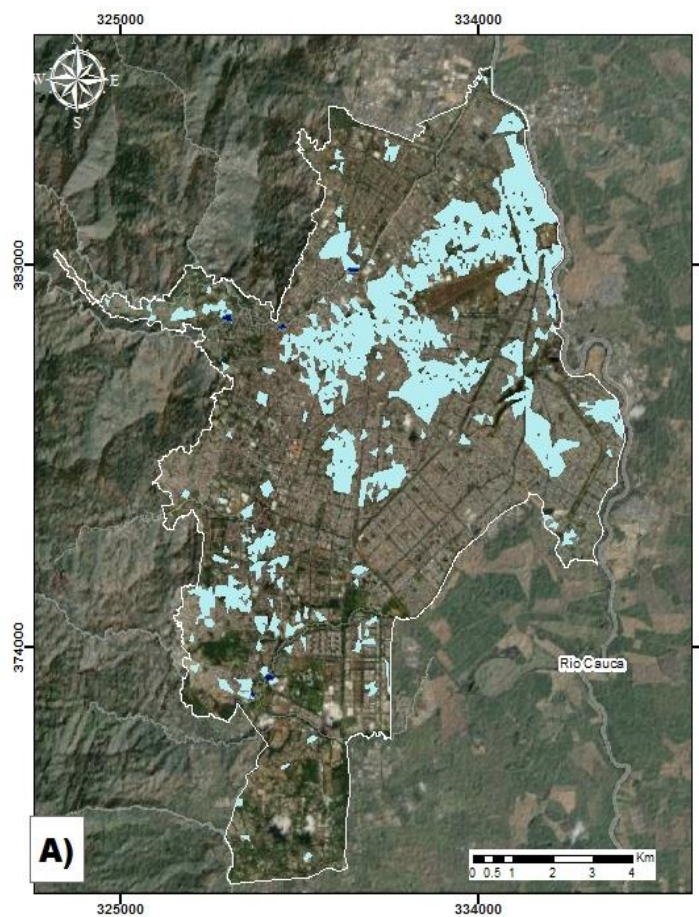

LEYENDA

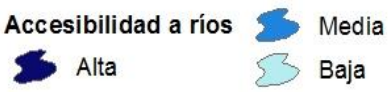

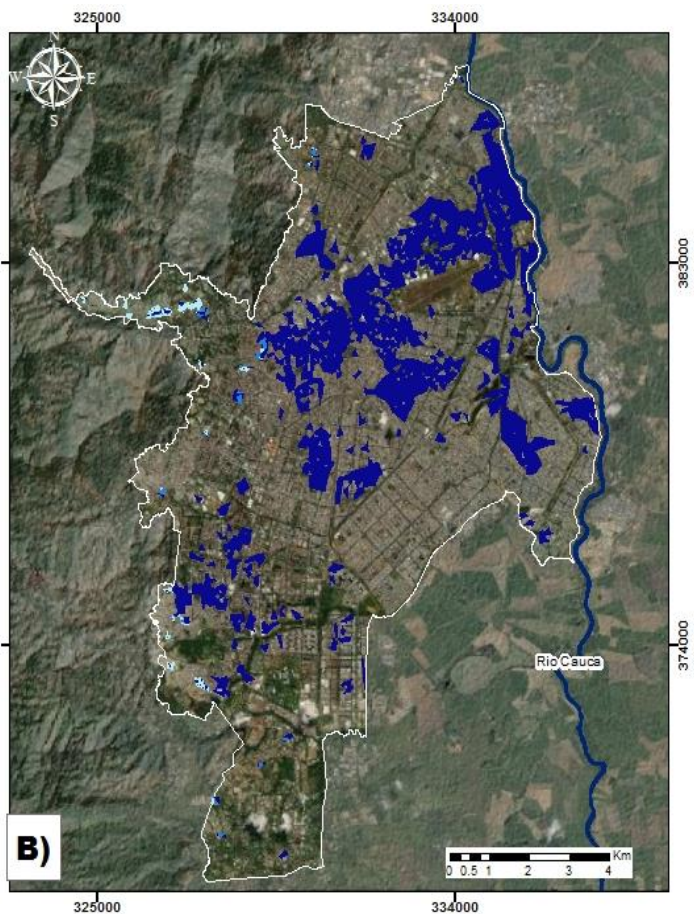

\section{LEYENDA}

Pendiente en porcentaje

Alta 0 a 7
Media 7,1 a 14

Baja 14,1 y más

Figura 5: Accesibilidad a ríos y pendiente en porcentaje

Fuente: Elaboración propia

Además de los ríos que hacen parte de la jurisdicción urbana es importante tener en cuenta los humedales y las quebradas, siendo puntos de regulación en el sistema hídrico. En la zona urbana hay 48 humedales, siendo las lagunas de regulación el Pondaje y Charco Azul ubicadas en el distrito de Agua Blanca (al oriente de la ciudad) las más grandes, con un área de 15 y 9.97 hectáreas aproximadamente (Alcaldía Municipal de Santiago de Cali, 2018). En la Figura 6 (A), los humedales desbordados son Charco Azul y el Pondaje. En correspondencia a las quebradas, estas provienen de la parte occidental que obedece al sector más alto de la ciudad, tiene meandros que recaen sobre antiguos recorridos de ríos y quebradas, los cuales recuperan su cauce al aumentar las precipitaciones (República de Colombia - INGEOMINAS-DAGMA, 2005). En la Figura 6 (B), los tramos de las quebradas que se rebosaron debido a la proximidad del cauce con el área de inundación. 


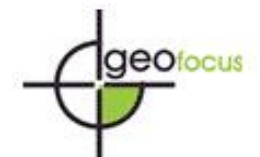

Sevillano Rodríguez, M. E. (2020): "Zonificación de la amenaza ante inundaciones a partir de un método de evaluación multicriterio en la ciudad de Santiago de Cali, Colombia", GeoFocus, n ${ }^{\circ}$ 25, p. 47-76. http://dx.doi.org/10.21138/GF.661
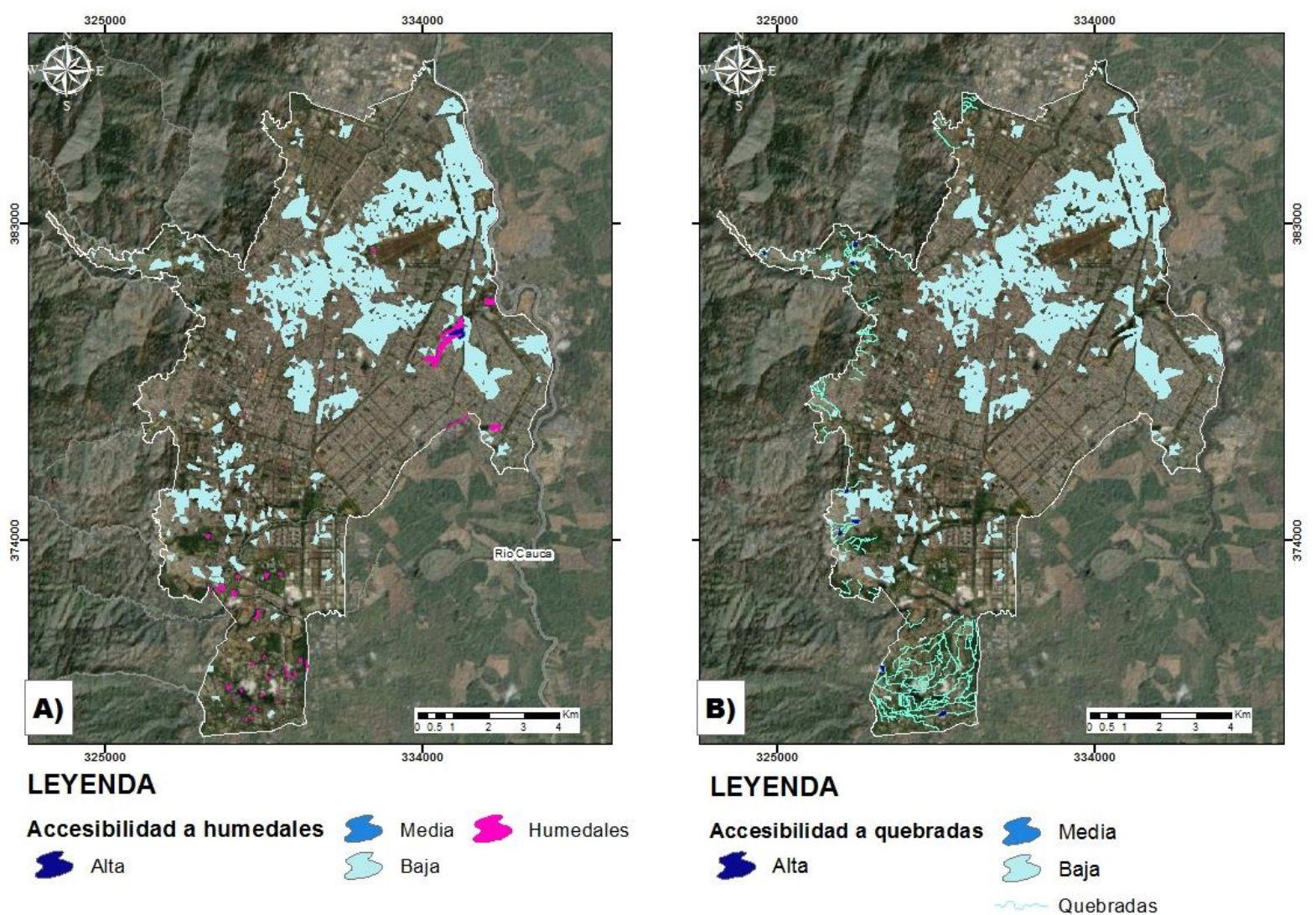

Figura 6: Accesibilidad a humedales y accesibilidad a quebradas Fuente: Elaboración propia

\subsection{Integración del modelo final}

Clasificado y definido los pesos de los criterios, se consiguió por medio de la aplicación de la sumatoria lineal ponderada, la zonificación de amenaza por inundación en Cali, Colombia, la cual revela la distribución del fenómeno en el área de estudio para un periodo de retorno con precipitaciones asociadas a este tipo de inundación de 1.1 (anual). Este mapa representa la combinación lineal de los factores según la ponderación establecida y por ello, refleja la distribución del territorio con mayor probabilidad a afectarse en caso de una ocurrencia y con base en las variables empleadas (véase Figura 7). El modelo se clasificó en tres categorías. El porcentaje de ocupación con respecto a la superficie total del área de inundación en hectáreas es de: Baja 1423 Ha (72\%), Media $436 \mathrm{Ha}(22 \%)$ y Alta $123 \mathrm{Ha}(6 \%)$. La mayor amenaza por inundación en la Figura 7 , se localiza en zonas con pendientes bajas $(0$ a $7 \%$ ) con proximidades de 0 a 60 metros a canales y fuentes hídricas y con profundidades de inundación mayores de $10 \mathrm{~cm}$. Localizadas con una extensión mayor en la parte oriental de la ciudad de Santiago de Cali. Al obtener esta cartografía se complementó con la información correspondiente a comunas para considerar donde se ubica el mayor grado de amenaza. La amenaza alta está presente en las comunas 2, 5, 6, 7, 8 y 12, con diferencia en la extensión de afectación. Mientras tanto, la amenaza de inundación media se localizó en 13 comunas de la ciudad. 


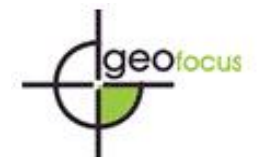

Sevillano Rodríguez, M. E. (2020): "Zonificación de la amenaza ante inundaciones a partir de un método de evaluación multicriterio en la ciudad de Santiago de Cali, Colombia", GeoFocus, no 25, p. 47-76. http://dx.doi.org/10.21138/GF.661
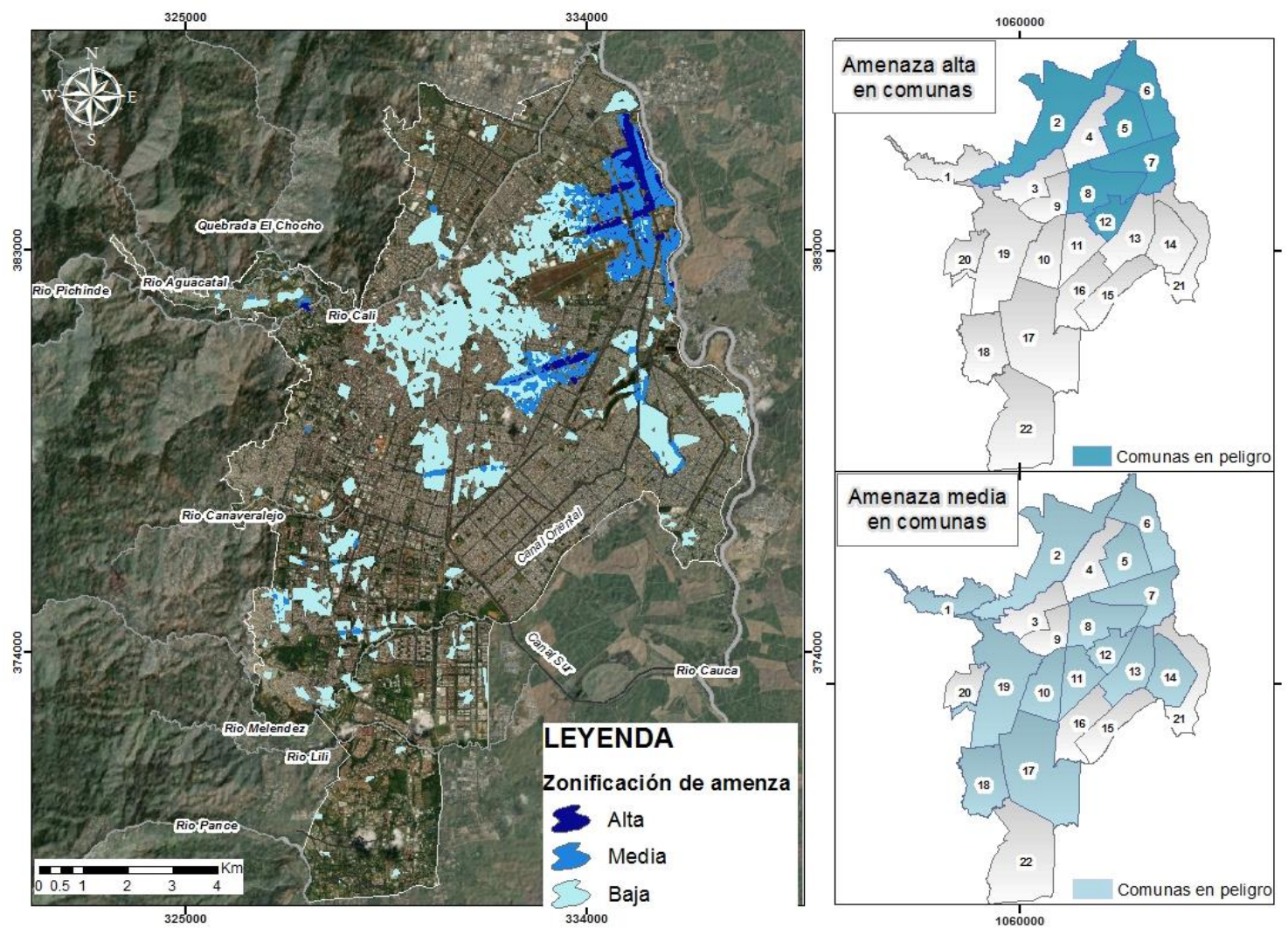

Figura 7: Amenaza por inundación

Fuente: Elaboración propia

El modelo anterior permite acercarse a la zonificación de amenaza por inundación considerando siete variables asociadas al tema. Atendiendo a la distribución espacial de las categorías obtenidas, merece destacar la importante relación entre cada una de ellas. La profundidad de inundación, es uno de los elementos de mayor jerarquía y coincide con las zonas que históricamente han sufrido los mayores daños debido a inundación. Además, de localizarse en los puntos finales de vertimiento de los principales canales de agua de la ciudad. En cuanto a los ríos, los lugares de crecida son: El río Cauca (barrio Puerto Nuevo), el río Cali (barrios San Vicente, el Peñón, Santa Rita y Santa Teresita) y el río Meléndez (Unicentro, Mayapan las Vegas y Sector Meléndez).

Además de observar la zonificación de amenaza en comunas, se representó cartográficamente los barrios expuestos al peligro de inundación. En Cali, muchas de las viviendas situadas al oriente, se construyeron en terrenos inundables (Vásquez, 1990), reportando en el periodo 1978 - 2000 entre 2 y 10 inundaciones (Jiménez, 2005). En la Figura 8, los sectores que presentan amenaza alta con afectación a 37 barrios en la zona urbana y la imagen del barrio Puerto nuevo, identificado con la aplicación del método de EMC y uno de los más perjudicados por el desbordamiento del río Cauca. La fotografía muestra la inundación producida el 12 de mayo de 2017 con afectación a más de 1000 familias que no lograron ingresar a sus viviendas durante tres días (Noticias Caracol, 2017). 


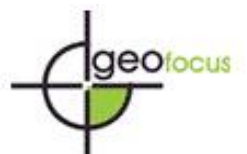

Sevillano Rodríguez, M. E. (2020): "Zonificación de la amenaza ante inundaciones a partir de un método de evaluación multicriterio en la ciudad de Santiago de Cali, Colombia", GeoFocus, $n^{\circ}$ 25, p. 47-76. http://dx.doi.org/10.21138/GF.661

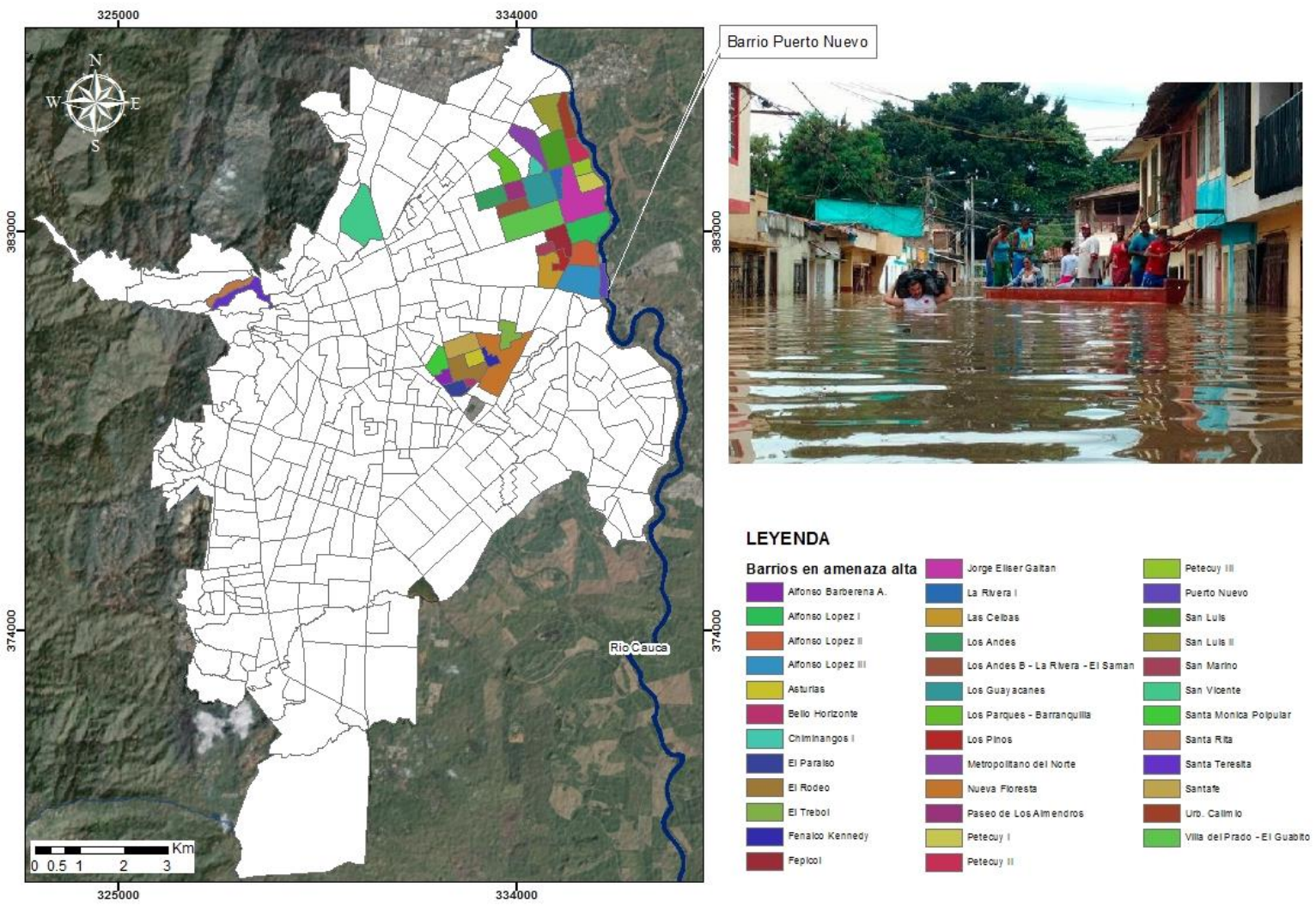

Figura 8: Sectores de barrios en amenaza alta

Fuente: Elaboración cartográfica propia; Fotografía de Noticias Caracol, 2017

Habría que decir también, que los sectores en amenaza media se ubican en su mayoría al oriente. En la Figura 9, los 96 barrios que se encuentran en amenaza media. En la misma imagen, las fotografías de los barrios San Luis II inundado desde el 14 de noviembre de 2017 (imagen registrada al día siguiente) (COLPRENSA/EL PAÍS, 2017) y el Guabal, con una inundación registrada en 1971 (Burbano, 1971). Durante 1986 y 1998, el barrio el Guabal fue uno de los más reportados por inundación (DESINVENTAR, 2018; República de Colombia-UNGRD, 2018), lo cual obedeció a su cercanía a uno de los colectores tributarios del canal Interceptor Sur. Sin embargo, la inundabilidad de este barrio ha ido disminuyendo conforme se han implementado un conjunto de diques y estrategias estructurales de control. 


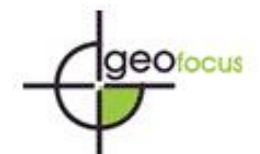

Sevillano Rodríguez, M. E. (2020): "Zonificación de la amenaza ante inundaciones a partir de un método de evaluación multicriterio en la ciudad de Santiago de Cali, Colombia”, GeoFocus, $n^{\circ}$ 25, p. 47-76. http://dx.doi.org/10.21138/GF.661

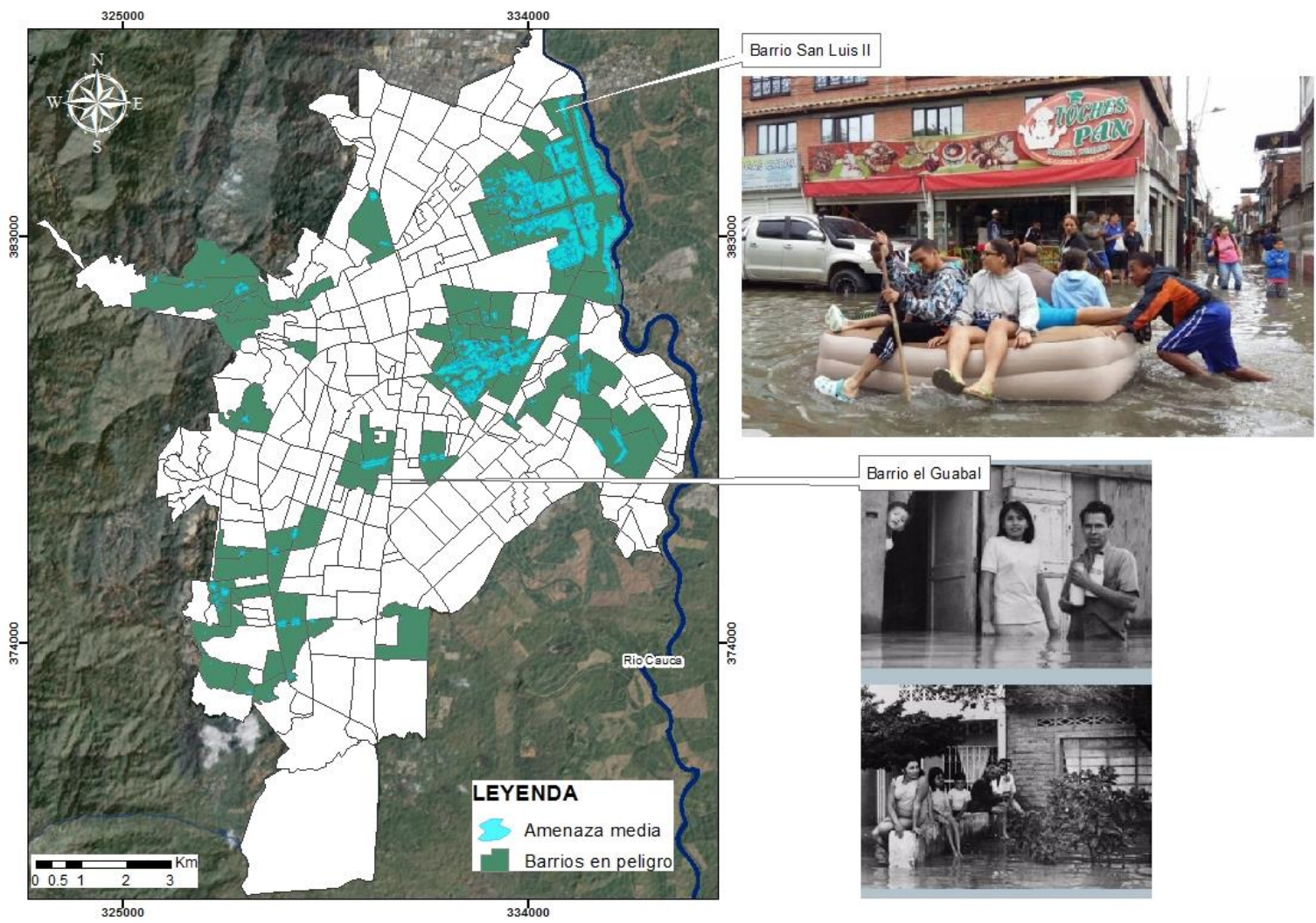

Figura 9: Sectores de barrios en amenaza media

Fuente: Elaboración cartográfica propia; Fotografía de COLPRENSA-EL PAÍS, 2017; Fotografía de Burbano, 1971

\section{Discusión y valoración de hallazgos}

Las inundaciones son uno de los peligros más frecuentes y devastadores del mundo. Por lo tanto, es necesario analizar el riesgo de inundación para responder a la sostenibilidad social, ambiental y económica de la mayoría de países (Shale-Ogato et al., 2020). En este campo, académicos de distintas profesiones han aportado a los estudios de amenazas, vulnerabilidades, riesgos y su mitigación a partir de procesos de ordenamiento territorial (Perles-Roselló et al., 2018). En este contexto, la evaluación integral del riesgo consta de muchos componentes, incluidos factores de peligro que originan los desastres, así como la valoración de la vulnerabilidad de los asentamientos que soportan el fenómeno (Wilchex-Chaux, 1993; Blaikie et al., 1996; Cardona, 2001; Cutter et al., 2003; Camarasa-Belmonte et al., 2008; Díez-Herrero et al., 2009; Perles-Roselló, 2010; PérezMorales et al., 2016; Perles-Roselló et al., 2017). De esta manera, la zonificación de amenaza por inundación es uno de los parámetros que debe sustentar el análisis de riesgo y las herramientas de planificación urbana (Rimba et al., 2017). En este trabajo se zonificó la amenaza por inundación a partir de EMC, durante el procedimiento metodológico se consideraron las variables profundidad de inundación, acumulación de flujo, inclinación de la pendiente, cercanía a canales y fuentes hídricas (ríos, humedales, quebradas) como factores importantes para la estimación del peligro. 


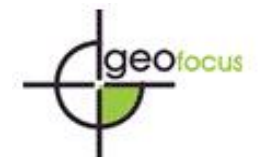

Revista Internacional de Ciencia y Tecnología de la Información Geográfica International Review of Geographical Information Science and Technology

Sevillano Rodríguez, M. E. (2020): "Zonificación de la amenaza ante inundaciones a partir de un método de evaluación multicriterio en la ciudad de Santiago de Cali, Colombia", GeoFocus, $n^{\circ}$ 25, p. 47-76. http://dx.doi.org/10.21138/GF.661

Con respecto a este tema investigadores de muchas partes del mundo han hecho aportes señalando la relevancia de la EMC en la valoración de riesgos asociados a fenómenos hidrometereológicos. Para Dang et al. (2011) la profundidad de inundación es un indicador principal, asumiendo que de esta condición dependen los daños a personas y bienes materiales. Según Sánchez \& MartínezGonzález (2014), la profundidad en compañía de la velocidad del flujo y la duración de la inundación permitieron determinar la inundabilidad pluvial en una cuenca en Coro, Venezuela. En cuanto a la acumulación de flujo Olivera-Acosta et al. (2011), la utilizaron como uno de los criterios hidrológicos junto a condiciones edáficas y geomorfológicas para aportar a la determinación de escenarios de peligro a inundaciones en la cuenca Guanabo en Cuba. Para estudiosos como González-Valencia (2006), el factor de pendientes tiene un papel importante para los resultados de vulnerabilidad física cuando se manejan en métodos de EMC. La variable pendiente fue empleada junto a parámetros de precipitación, red de drenaje, tipo de suelo y cubierta vegetal por Yahaya et al. (2010) para el análisis de inundabilidad en Nigeria. También, en Malasia, Japón e India recurrieron a criterios similares a los propuestos por Yahaya (Abdalla-Elsheikh et al., 2015; Rimba et al., 2017; Shale-Ogato et al., 2020).

Tal como lo menciona Rimba et al. (2017), la pendiente es un elemento significativo para determinar la velocidad y la duración del flujo de agua, ya que las inundaciones son más riesgosas en las áreas planas que en las superficies más empinadas. La cercanía a fuentes hídricas (ríos, humedales, quebradas), reflejan una exposición mayor cuando la distancia es menor. Para Siddayao et al. (2014), la distancia a ríos es el factor que más contribuyó al desastre por inundación en el municipio de Enrile en la provincia de Cagayan, norte de Filipinas. En lo que se refiere a esto Chávez-Cortés et al. (2017), plantearon que en la subcuenca del río Atoyac-Oaxaca de Juárez, México, las áreas menos inundables tienen distancias mayores a 2300 metros de los cuerpos de agua, perteneciendo a zonas con pendientes pronunciadas. Los canales son entendidos en el caso particular de este estudio como conductos que pueden ser abiertos o cerrados, construidos para direccionar las aguas lluvias y algunos afluentes de ríos de primer orden (común en ciudades donde confluyen muchas fuentes hídricas).

Bajo esta última consideración, ninguno de los autores tiene en cuenta la variable de canales lo cual se relaciona con que la mayoría de estudios se centran en la zonificación de inundación en cuencas, subcuencas y municipios y dicho factor podría sustraerse de los indicativos de la red de drenaje y fuentes hídricas. Hasta aquí, los estudios de EMC para la zonificación de amenaza por inundación, han dependido básicamente de los métodos hidrológicos utilizando parámetros de estimación de profundidad, velocidad y duración de la inundación (Dang et al., 2011; Sánchez-Román, 2012; Sánchez \& Martínez-González, 2014) y, métodos geomorfológicos con indicadores de pendientes, cobertura de suelo, tipos de suelo, geología, geomorfología y edafología que se han fortalecido con la incorporación de factores de precipitación, red de drenaje, distancia a fuentes hídricas, acumulación del flujo, abatimiento a recursos hídricos (González-Valencia, 2006; Yahaya et al., 2010; Olivera-Acosta et al., 2011; Siddayao et al., 2014; Mendoza-Mejía \& Orozco-Hernández, 2014; Abdalla-Elsheikh et al., 2015; Shale-Ogato et al., 2020). En el mismo sentido, pero con técnicas diferentes Shivaprasad-Sharma et al., (2018) clasificó la inundabilidad en Kopili India, usando capas de inundación históricas multitemporales derivadas de imágenes de satélite. Cada uno de los modelos anteriores son muy interesantes pero presentan diferencias en la utilización de variables para el análisis de EMC. 


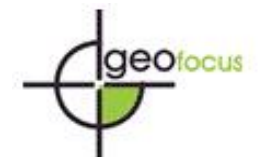

Revista Internacional de Ciencia y Tecnología de la Información Geográfica International Review of Geographical Information Science and Technology

Sevillano Rodríguez, M. E. (2020): "Zonificación de la amenaza ante inundaciones a partir de un método de evaluación multicriterio en la ciudad de Santiago de Cali, Colombia", GeoFocus, $n^{\circ}$ 25, p. 47-76. http://dx.doi.org/10.21138/GF.661

En este orden, la utilización de EMC, resulta útil para la zonificación de amenaza por inundación en zonas urbanas y el principal aporte de este trabajo radica en la posibilidad de integrar a partir de un análisis jerárquico multicriterio, datos hidrológicos como lo son la profundidad de la inundación, acumulación de flujo. Las pendientes como un factor geomorfológico y la distancia a fuentes hídricas y canales como elementos que fortalecen el método en un contexto urbano. Todas estas condiciones tomando como base la identificación del área inundable a partir de imágenes de satélite. Así las cosas, en la aplicación de un modelo multicriterio para la zonificación de peligro en la ciudad de Cali, Colombia, fue posible determinar tres condiciones de amenaza: La amenaza clasificada como alta ocupa el $6 \%$ de la superficie inundable, la media $22 \%$ y la baja $72 \%$. Las áreas con amenaza alta están asociadas a las pendientes más bajas. En esta zona, el agua se acumula alcanzando profundidades de inundación que superan los 10 centímetros, con distancias de menos de 60 metros a canales, ríos, humedales y quebradas. La mayoría de los 37 barrios expuestos se ubican al oriente, sobre la llanura inundable del río Cauca y la zona de confluencia del canal Oriental (comunas 5, 6, 7, 8 y 12). Asimismo, en la parte occidental sobre el río Cali (comuna 2).

La amenaza media está asociadas fundamentalmente a pendientes más pronunciadas que por sus características morfológicas no permiten que el agua se deposite en su totalidad (Dewan, 2013; Chávez-Cortés, et al., 2017). La profundidad se encuentra entre 5,1 y 10 centímetros. En la zona media de inundación, la distancia a canales y redes hídricas es mayor. Esto indica que las afectaciones a personas y bienes pueden ser menores en términos cualitativos y las deficiencias podrían ser resueltas en menor tiempo en comparación a la amenaza alta. Sin embargo, en este caso la peligrosidad corresponde al $22 \%$ de la superficie inundable afectando a 96 barrios localizados en las zonas adyacentes a los ríos y canales (Comunas 1, 2, 5, 6, 7, 8, 10, 11, 12, 13, 14, 17, 18 y 19) siendo visiblemente más afectadas las comunas 5, 6, 7, 8 y 12 (debido a que el área inundada es mayor). La menor amenaza, tienen distancias de 90 metros a cuerpos de agua y canales, perteneciendo a las pendientes más altas ubicadas al occidente con profundidades de inundación de menos de 5 centímetros que generalmente se ubican en pendientes más pronunciadas con baja capacidad de acumular agua y mayor posibilidad de escurrimiento (Chávez-Cortés, et al., 2017).

Se debe agregar que, al igual que el estudio de parámetros físicos para la evaluación del peligro es necesario estudiar el crecimiento físico de las ciudades y los usos apropiados de suelo en correspondencia a la ocupación de terrenos no habilitados ambientalmente para su edificación. Más aún, cuando la urbanización es una característica que define el crecimiento demográfico y aumenta el riesgo por inundación (Santato et al., 2013). Para Hernández \& Vieyra (2010), la fragilidad humana ante el peligro se incrementa cuando cambia el crecimiento de la población y el patrón de asentamiento. De manera que, Santiago de Cali, ha experimentado una expansión física debido al crecimiento exponencial de su población principalmente en zonas periféricas (Sevillano-Rodríguez \& Bravo-Peña, 2018), lo que ha significado la construcción de viviendas, que en ciertos casos, se han establecido en lugares que no son aptos (Vásquez, 1990; Alcaldía municipal de Santiago de Cali - DAGMA, 2011 Corporación OSSO; Royal HaskoningDHV, 2013). Es decir, ha generado un grado de exposición mayor ante los riesgos ambientales. 


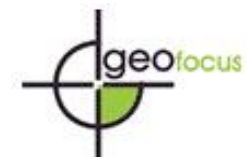

Revista Internacional de Ciencia y Tecnología de la Información Geográfica International Review of Geographical Information Science and Technology

Sevillano Rodríguez, M. E. (2020): "Zonificación de la amenaza ante inundaciones a partir de un método de evaluación multicriterio en la ciudad de Santiago de Cali, Colombia", GeoFocus, $n^{\circ}$ 25, p. 47-76. http://dx.doi.org/10.21138/GF.661

\section{Conclusiones}

El estudio se centró en zonificar la amenaza por inundación en la ciudad de Santiago de Cali, Colombia, siguiendo un método de EMC en el cual se utilizaron siete variables de análisis (profundidad, acumulación de flujo, pendientes y distancia a canales, ríos, humedales y quebradas). La zonificación de la zona inundable se clasificó en amenaza alta $6 \%$ (123 Ha), media $22 \%$ (436 Ha) y baja $72 \%$ (1423 Ha) con un periodo de retorno de precipitaciones asociadas de 1.1 anual. Los resultados reflejaron que las mayores afectaciones se localizan en asentamientos ubicados en las comunas 2, 5, 6, 7, 8 y 12. La relevancia de estas deducciones reside en la utilidad que tienen para la gestión de riesgos, zonificaciones que integren parámetros asociados a inundaciones pluviales y fluviales para Cali, donde ninguno de los estudios implementados anteriormente por parte del gobierno municipal han determinado en una misma base cartográfica la inundabilidad urbana, teniendo en consideración todas las fuentes hídricas y los canales que hacen parte de la dinámica de la ciudad. La zonificación de inundación a partir de un método de EMC, demostró ser un instrumento apropiado para la valoración de zonas inundables y su clasificación.

Conviene subrayar que el análisis de riesgo en su conjunto debe corresponder a observaciones de condiciones amenazantes, así como también a estudios de vulnerabilidad social. En este estudio, la integración de criterios en sistemas de información geográfica fue adecuada para establecer la peligrosidad por inundaciones. Por lo tanto, la zonificación de amenaza o peligro por inundación resulta ser un elemento importante pero requiere ser complementado bajo la premisa de un modelo integral y aplicado que aporte a los procesos de planificación y ordenamiento del territorio. Así, respondería a la protección de vidas y demás elementos expuestos en situaciones de riesgo por inundación que, han sido agravados con el crecimiento urbano desordenado experimentado por la ciudad. A causa de esto, el siguiente paso en trabajos próximos deberá ser valorar la vulnerabilidad y riesgo de inundación para la ciudad de Cali, Colombia.

Agradecimientos: El presente documento hace parte de los avances parciales de investigación para obtener el grado de Doctora en Estudios Urbanos por la Universidad Autónoma de Ciudad Juárez. Se agradece al CONACYT por la beca brindada a la doctorante, al convenio CLACSO-CONACYT por la estancia académica, al grupo de líderes por el acompañamiento en campo, a los tutores internos y externos y demás apoyos de Investigación.

\section{Referencias bibliográficas}

Abdalla-Elsheikh, R. F., Ouerghi, S., \& Elhag, A. R. (2015): "Flood risk map based on GIS and multicriteria techniques (Case Study)", Journal of Geographic Information System, 7, pp. 348-357.

Alcaldía de Santiago de Cali - DAGMA. (2010): Balance hídrico de las aguas subterráneas: Municipio de Santiago de Cali. Santiago de Cali, DAGMA.

Alcaldía de Santiago de Cali. (2018): Informe anual homicidios. Santiago de Cali, Alcaldía Municipal de Santiago de Cali. Disponible en http://www.cali.gov.co/documentos/1201/informesanual-homicidios/ (Consultado 05-03-2018). 


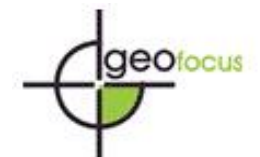

Revista Internacional de Ciencia y Tecnología de la Información Geográfica International Review of Geographical Information Science and Technology

Sevillano Rodríguez, M. E. (2020): "Zonificación de la amenaza ante inundaciones a partir de un método de evaluación multicriterio en la ciudad de Santiago de Cali, Colombia", GeoFocus, no 25, p. 47-76. http://dx.doi.org/10.21138/GF.661

Alcaldía municipal de Santiago de Cali - DAGMA. (2011): Estudio hidrológico e hidráulico rio Aguacatal a su paso por el área urbana de Santiago de Cali. Santiago de Cali, Alcaldía Municipal de Santiago de Cali. Disponible http://www.cali.gov.co/publico2/documentos/dagma/estudios_ambientales/ESTUDIOCONTRATO 460_2011PARTE22011.pdf (Consultado 08-08-2019).

Alcaldía Municipal de Santiago de Cali - IDESC. (2014): Geovisor IDESC. Santiago de Cali, Alcaldía Municipal de Santiago de Cali. Disponible en http://idesc.cali.gov.co/geovisor.php (Consultado 01-01-2019).

Alcaldía Municipal de Santiago de Cali. (2014): Plan de Ordenamiento Territorial del municipio de Santiago de Cali. Santiago de Cali, Departamento Administrativo de Planeación Municipal.

Alcaldía Municipal de Santiago de Cali. (2018): Inventario de humedales en la zona urbana. Santiago de Cali, DAGMA

Alcaldía municipal de Santiago de Cali-PMGRD. (2018): Plan de gestión del riesgo de desastres. Santiago de Cali. Santiago de Cali, Secretaria de Gestión del Riesgo Emergencias y Desastres.

Anusha, N., \& Bharathi, B. (2019): Flood detection and flood mapping using multi-temporal synthetic aperture radar and optical data. The Egyptian Journal of Remote Sensing and Space Science. Disponible en https://doi.org/10.1016/j.ejrs.2019.01.001 (Consultado 05-05-2020.

Banco Mundial Colombia y GFDRR. (2012): Análisis de la gestión del riesgo de desastres en Colombia: Un aporte a la construcción de políticas públicas. Bogotá, Banco Mundial.

Barrantes-Castillo, G., \& Vargas-Bogantes, J. (2011): "La zonificación de amenaza por inundación como herramienta para el ordenamiento territorial en valle del río Xixaola", Revista Geográfica, 1, 46, pp. 67-85.

Barredo-Cano, J. I. (1996): Sistemas de información geográfica y evaluación multicriterio en la ordenación del territorio. España, RA-MA.

Belmonte, L., \& Caamaño, S. (2009): Una aplicación basada en imágenes SAR para el monitoreo y prevención de las inundaciones en Argentina (Tesis de pregrado). Córdoba, Universidad Nacional

Benito, G. (2007): "Riesgo de inundaciones: Tendencias históricas y perspectivas de acuerdo con el Cambio Climático", Cuaternario \& Geomorfología, 20, 3-4, pp. 29-44.

Blaikie, P., Cannon, T., David, I., \& Wisner, B. (1996): Vulnerabilidad: El entorno social, político y económico de los desastres. LA RED. Disponible en https://www.desenredando.org/public/libros/1996/vesped/vesped-todo_sep-09-2002.pdf

(Consultado 05-10-2018).

Calderón, D., \& Frey, K. (2017): "El ordenamiento territorial para la gestión del riesgo de desastres", Territorios, 36, pp. 239-264.

Camarasa-Belmonte, A. M., \& Soriano-García, J. (2008): "Peligro, vulnerabilidad y riesgo de inundación en ramblas mediterráneas: Los llanos de Carraixet y Poyo", Cuadernos de Geografía, 83, pp. 1-26.

Cardona, O. D. (2001): Estimación holística del riesgo sísmico utilizando sistemas dinámicos complejos (Tesis doctoral). Barcelona, Universidad Politécnica de Cataluña. 


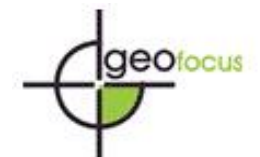

Revista Internacional de Ciencia y Tecnología de la Información Geográfica International Review of Geographical Information Science and Technology

Sevillano Rodríguez, M. E. (2020): "Zonificación de la amenaza ante inundaciones a partir de un método de evaluación multicriterio en la ciudad de Santiago de Cali, Colombia", GeoFocus, $n^{\circ}$ 25, p. 47-76. http://dx.doi.org/10.21138/GF.661

Cartaya, S., \& Mantuano-Duarte, R. (2016): "Identificación de zonas en riesgo de inundación mediante la simulación hidráulica en un segmento del río Pescadillo, Manabí, Ecuador", Revista de investigación, 4, 89, pp. 158-170.

CEPAL \& BID. (2012): Valoración de daños y pérdidas. Ola invernal en Colombia 2010-2011. Bogotá, Naciones Unidas.

CEPAL. (2002): Políticas públicas para la reducción de la vulnerabilidad frente a los desastres naturales y socionaturales. Santiago de Chile, CEPAL.

Chávez-Cortés, M. M., Binnquist-Cervantes, G., \& Salas-Flores, A. C. (2017): "Evaluación multicriterio de la vulnerabilidad biofísica ante inundaciones en la subcuenca río Atoyac-Oaxaca de Juárez", Ecosistemas y recursos agropecuarios, 4, 10, pp. 97-109.

Cooperación Alemana al Desarrollo-GTZ. (2010): Incorporar la gestión del riesgo en la planificación territorial orientaciones para el nivel municipal. Lima, GTZ.

Corporación OSSO y Royal HaskoningDHV. (2013): Diagnóstico y recomendaciones para el Jarillón de Aguablanca en el municipio de Cali. Santiago de Cali, Alcaldía Municipal de Santiago de Cali.

Cutter, S. L., Boruff, B. J., \& Shirley, W. L. (2003): "Social vulnerability to environmental Hazards", Social Science, 84, 2, pp. 242-261.

Da Silva, C. J., \& Cardozo, O. D. (2015): "Evaluación multicriterio y sistemas de información geográfica aplicados a la definición de espacios potenciales para el uso del suelo residencial en Resistencia (Argentina)", Geofocus, 16, pp. 23-40.

Dang, N. M., Babel, M., \& Huynh. (2011): "Evaluation of food risk parameters in the Day River Flood Diversion Area, Red River Delta, Vietnam”, Natural Hazards, 56, 1, pp. 169-194.

Delgado, J. F., \& Quintero, O. Y. (2013): “Aplicación de la teledetección y los sistemas de información geográfica en la interpretación de zonas inundables. Caso de estudio: Río Soapaga, Sector Paz de río Boyacá", Ciencia e Ingeniería Neogranadina, 23, 2, pp. 55-76.

DESINVENTAR. (2018): Inventario histórico de registros de inundación. DESINVENTAR. Disponible en https://online.desinventar.org/desinventar/\#COL-1250694506colombia_inventario_historico_de_desastres (Consultado 03-05-2018).

DESINVENTAR. (2019). Inventario histórico nacional de desastres por inundación 1914-2018. DESINVENTAR.]. Disponible en https://online.desinventar.org/desinventar/\#COL-1250694506colombia inventario historico de desastres (Consultado 20-12-2019).

Dewan, A. (2013): Floods in a megacity geospatial technique in assessing hanzards, risk and vulnerability. Netherlands, Springer.

Díez-Herrero, A., Llorente, M., Ballesteros-Canovas, J. A., \& Ruiz-Villanueva, V. (2009): "Riesgos por avenidas e inundaciones fluviales", Enseñanza de las ciencias de la tierra, 173, pp. 254-263.

[Fotografía de COLPRENSA/EL PAÍS]: Inundación en barrio Puerto Nuevo en 2017, Santiago de Cali., Archivos fotográficos de COLPRENSA/EL PAÍS.]. Disponible en https://www.elcolombiano.com/colombia/aguacero-en-cali-equivale-a-lluvias-de-un-mes-

DF7700126 (Consultado 10-12-2019 


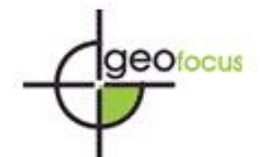

Revista Internacional de Ciencia y Tecnología de la Información Geográfica International Review of Geographical Information Science and Technology

Sevillano Rodríguez, M. E. (2020): "Zonificación de la amenaza ante inundaciones a partir de un método de evaluación multicriterio en la ciudad de Santiago de Cali, Colombia", GeoFocus, $n^{\circ}$ 25, p. 47-76. http://dx.doi.org/10.21138/GF.661

[Fotografía de José Burbano]: Inundación barrio el Guabal en 1971, Santiago de Cali. 1971, Archivo fotográfico de Crónicas de barrio.

[Fotografía de Noticias Caracol]: Inundación barrio Puerto Nuevo en 2017, Santiago de Cali, Archivos fotográficos de Noticias Caracol. Disponible en https://noticias.caracoltv.com/cali/inundaciones-que-no-cesan-danaron-celebracion-de-dia-de-lamadre-en-puerto-nuevo-nororiente-de-cali (Consultado 15-02-2020).

Gao, J., Nickum, J. E., \& Pan, Y. (2007): "An assessment of flood hazard vulnerability in the Dongting Lake Region of China", Lake Reservoirs: Science, Policy and Management for Sustainable, 12, 1, pp. 27-34.

García de León, A., \& Humacata, L. (2019): “Clasificación espacial esploratoria y multivariada con sistemas de información geográfica”, en G. Buzai, L. Humacata, S. Lanzelotti, E. M. Galbán, \& N. Principi, Teoria y métodos de la geografía cuantitativa. Buenos Aires, Instituto de Investigaciones Geográficas Universidad de Luján, pp. 1-227.

Gobierno de España-Ministerio de Medio Ambiente \& Medio Rural Marino. (2011): Guía metodológica para el desarrollo del sistema nacional de cartografía de zonas inundables. Madrid, Ministerio de Medio Ambiente y Medio Rural y Marino.

González-Valencia, J. E. (2006): "Propuesta metodológica basada en un análisis multicriterio para la identificación de zonas de amenaza por deslizamientos e inundaciones", Revista de Ingenierías, 5, 8, pp. 59-70.

Hernández, J., \& Vieyra, A. (2010): "Riesgo por inundaciones en asentamientos precarios del periurbano. Morelia, una ciudad media mexicana. ¿El desastre nace o se hace?”, Revista de Geografia Norte Grande, 47, pp. 45-62.

Jiménez, N. (2005): Elementos históricos y urbanos en la generación de desastres por inundaciones y deslizamientos en Cali 1950 - 2000 (Tesis de pregrado). Santiago de Cali, Universidad del Valle.

Ley, J. G., \& Calderón, G. A. (2008): "De la vulnerabilidad a la producción del riesgo en las tres primeras décadas de la ciudad de Mexicali, 1903-1933", Región y sociedad, 20, 41, pp. 145-173.

Li, Y., Martinis, S., \& Wieland, M. (2019): "Urban flood mapping with an active self-learning convolutional neural network based on TerraSAR-X intensity and interferometric coherence", ISPRS Journal of Photogrammetry and Remote Sensing, 152, pp. 178-191.

Lorenzo, P. F., \& Hernández, N. D. (2018): "Mapeo de áreas inundadas utilizando imágenes de radar TanDEM-X en Acapulco de Juárez, Guerrero-México", Terra Digitalis, 2, 1, pp. 1-7.

Macchione, F., Costabile, P., Costanzo, C., \& De Lorenzo, G. (2019): "Extracting quantitative data from non-conventional information for the hydraulic reconstruction of past urban flood events. A case study", Journal of Hydrology, 576, pp. 443-465.

Martínez-González, D. J., \& Castrillón- Cruz, D. A. (2014): Zonificación de amenaza por inundaciones en la zona urbana y de expansión del municipio de Jamundí (Valle del Cauca) (Tesis de licenciatura). Santiago de Cali, Universidad del Valle.

Masgrau, L. R. (2004): "Los mapas de riesgo de inundaciones: Representación de la vulnerabilidad y aportación de la vulnerabilidad y aportación de las innovaciones tecnológicas", Anál.Geogr, 43, pp. 153-171. 


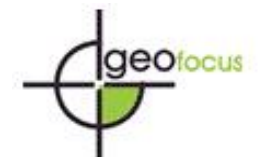

Revista Internacional de Ciencia y Tecnología de la Información Geográfica International Review of Geographical Information Science and Technology

Sevillano Rodríguez, M. E. (2020): "Zonificación de la amenaza ante inundaciones a partir de un método de evaluación multicriterio en la ciudad de Santiago de Cali, Colombia", GeoFocus, $n^{\circ}$ 25, p. 47-76. http://dx.doi.org/10.21138/GF.661

Massiris, Á. C. (2005): Fundamentos conceptuales y metodológicos para el ordenamiento territorial. Tunja, Universidad Pedagógica y Tecnológica de Colombia.

Materón, H., García, J. L., Arango, D., \& Parra, D. (2006): "Modelación hidrológica e hidráulica aplicada a estudios de inundabilidad en cauces naturales caso de estudio: Urbanización río Nima", Ingeniería de recursos naturales y del ambiente, 5, pp. 27-38.

Mendoza-Mejía, J. B., \& Orozco-Hernández, M. E. (2014): “Análisis de la vulnerabilidad biofísica a los riesgos por inundación en la zona metropolitana de Toluca, México", Luna Azul, 38, pp. 86104.

Meyer, V., Scheuer, S., \& Haase, D. (2008): "A multicriteria approach for flood risk mapping exemplified at the Mulde river, Germany", Natural Hazards, 48, pp. 17-39.

Narváez, L., Lavell, A., \& Pérez, G. (2009): La gestión del riesgo de desastres. Un enfoque basado en procesos. Lima, Comunidad Andina.

NASA (2018): Geoportal NASA-EARTHDATA, NASA. Disponible en https://www.asf.alaska.edu/. (Consultado 10-03-2018).

Olcina-Cantos, J. (2008): "Cambios en la consideración territorial, conceptual y de método de los riesgos naturales”, Scripta Nova, 270, 24, pp. 478-545.

Olcina-Cantos, J. (2017): "Incremento de episodios de inundación por lluvias de intensidad horaria en el sector central del litoral mediterráneo español: análisis de tendencias en Alicante", Ciencias Social e humanidades, 29, pp. 143-163.

Olcina-Cantos, J., \& Díez-Herrero, A. (2017): "Cartografía de inundaciones en España", Estudios Geográficos, 78, 282, pp. 283-315.

Olivera-Acosta, J., Morales, G. M., García-Rivero, A. E., Salgado, E. J., López, M. L., Estrada, R., \& Dueñas, M. C. (2011): El uso de los SIG y la evaluación multicriterio (EMC) para la determinación de escenarios de peligros de inundaciones en cuencas fluviales. Estudio de caso cuenca Guanabo.ciudad de la Habana. La Habana. X Congreso Cubano de Informática y Geociencias (Geoinfo'2011). Disponible en http://www.redciencia.cu/geobiblio/paper/2011_Olivera_GEOINF-O8.pdf (Consultado 20-112018).

Ollero-Ojeda, A. (2015): "Un necesario cambio de visión y de estrategia en la gestión de las inundaciones", Tecnoaqua, 12, pp. 122-124.

Pérez-Morales, A. P. (2012): "Estado actual de la cartografía de los riesgos de inundación y su aplicación en la ordenación del territorio. Caso de la región Murcia", Boletín de la Asociación de Geógrafos Españoles, 58, pp. 57-84.

Pérez-Morales, A., Navarro-Hervás, F., \& Álvarez-Rogel, Y. (2016): "Propuesta metodológica para la evaluación de la vulnerabilidad social en poblaciones afectadas por el peligro de inundación: el caso de Águilas (Murcia, sureste ibérico)", Documents d'Anàlisi Geográfica, 62, 1, pp. 133-159.

Perles-Roselló, M. J. (2010): “Apuntes para la evaluación de la vulnerabilidad social frente al riesgo de inundación”, Baetica. Estudios de historia moderna y contemporánea, 32, pp. 67-87. 


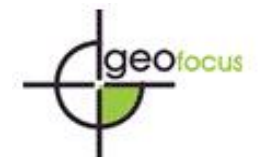

Revista Internacional de Ciencia y Tecnología de la Información Geográfica International Review of Geographical Information Science and Technology

Sevillano Rodríguez, M. E. (2020): "Zonificación de la amenaza ante inundaciones a partir de un método de evaluación multicriterio en la ciudad de Santiago de Cali, Colombia", GeoFocus, n ${ }^{\circ}$ 25, p. 47-76. http://dx.doi.org/10.21138/GF.661

Perles-Roselló, M. J., Gallejos-Reina, A., \& Cantero-Prados, F. (2006): “Análisis del ajuste del área inundable obtenida mediante evaluación integrada de peligrosidad de inundación y peligros asociados", Baetica. Estudios de Arte, Geografía e Historia, 28, pp. 527-545.

Perles-Roselló, M. J., Olcina-Cantos, J., \& Mérida- Rodríguez, M. (2018): “Balance de las políticas de gestión del riesgo de inundaciones en España. De las acciones estructurales a la ordenación territorial. Ciudad y territorio", Estudios Territoriales, 197, pp. 417-438.

Perles-Roselló, M., Sortino-Barrionueno, J., \& Canteros-Prados, F. (2017): "Cartografía de la vulnerabilidad del territorio frente al riesgo de inundación. Propuesta adaptada a la directiva europea de inundaciones y normativas derivadas", Boletín de Asociación de Geógrafos Españoles, 75, pp. 341-372.

República de Colombia - INGEOMINAS-DAGMA. (2005): Estudio de microzonificación sísmica de Santiago de Cali. Bogotá, INGEOMINAS-DAGMA. Disponible en https://repositorio.gestiondelriesgo.gov.co/handle/20.500.11762/19833 (Consultado 21-09-2018).

República de Colombia-DANE. (2018): Sistema de consulta información censal. Censo de población y vivienda 2018, DANE. Disponible en https://www.dane.gov.co/index.php/estadisticaspor-tema/demografia-y-poblacion/censo-nacional-de-poblacion-y-vivenda-2018 (Consultado 10-072019).

República de Colombia- Decreto 2245. (2017): Decreto 2245 de 2017. Bogotá, Congreso de Colombia.

Disponible

en https://www.funcionpublica.gov.co/eva/gestornormativo/norma.php?i=85056 (Consultado 10-032019).

República de Colombia. (1997): Ley 388 de 1997 de ordenamiento territorial. Bogotá, Congreso de Colombia. Disponible en https://www.minambiente.gov.co/images/normativa/leyes/1997/ley_0388_1997.pdf (Consultado 10-03-2019).

República de Colombia. (2007): Decreto 3600 de 2007. Bogotá, República de Colombia. Disponible en http://www.minambiente.gov.co/images/normativa/decretos/2007/dec_3600_2007.pdf (Consultado 10-03-2019).

República de Colombia. (2011): Ley 1454 de 2011, Ley orgánica de ordenamiento territorial. Bogotá, Congreso de Colombia. Disponible en https://observatorioplanificacion.cepal.org/sites/default/files/instrument/files/2011.\%20LOOT.pdf (Consultado 10-03-2019).

República de Colombia. (2012): Ley 1523 de 2012. Bogotá, Congreso de Colombia. Disponible en http://www.secretariasenado.gov.co/senado/basedoc/ley 1523 2012.html (Consultado 10-03-2019).

República de Colombia-Decreto 2811. (1974): Decreto 2811 de 1974. Bogotá, República de Colombia.

Disponible

en http://www.secretariasenado.gov.co/senado/basedoc/decreto_2811_1974.html (Consultado 10-032019).

República de Colombia-IDEAM. (2017): Guía metodológica para la elaboración de mapas de inundación. Bogotá: IDEAM. 


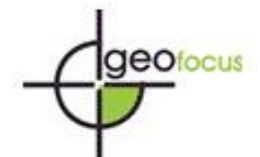

Revista Internacional de Ciencia y Tecnología de la Información Geográfica

International Review of Geographical Information Science and Technology

Sevillano Rodríguez, M. E. (2020): "Zonificación de la amenaza ante inundaciones a partir de un método de evaluación multicriterio en la ciudad de Santiago de Cali, Colombia", GeoFocus, n ${ }^{\circ}$ 25, p. 47-76. http://dx.doi.org/10.21138/GF.661

República de Colombia-UNGRD. (2015): Guía de integración de la gestión del riesgo de desastres y el ordenamiento territorial municipal. Bogotá, UNGRD. Disponible en http://portal.gestiondelriesgo.gov.co/ (Consultado 02-11-2018).

República de Colombia-UNGRD. (2018): Unidad Nacional para la gestión del riesgo de desastres: Reportes de inundación 2013-2018 por municipios. Bogotá, UNGRD. Disponible en http://portal.gestiondelriesgo.gov.co/ (Consultado 20-09-2018).

Rimba, A. B., Setiawati, M. D., Sambah, A. B., \& Miura, F. (2017): "Physical flood vulnerability mapping applying geospatial techniques in Okazaki city, Aichi prefecture, Japan", Urban Sci, 1, 7, pp. $1-22$.

Rodríguez-Gaviria, E. M. (2016): Diseño metodológico para la evaluación de riesgo por inundación con información escasa (Tesis de Doctorado). Medellín, Universidad Nacional de Colombia.

Rubiano-Vargas, D. M., \& Ramírez-Cortés, F. (2009): Incorporando la gestión del riesgo de desastres en la planificación y gestión territorial. Guía técnica para la interpretación y aplicación del análisis de amenazas y riesgos. Lima, Comunidad Andina.

Saaty, T. (1980): The analytic hierarchy process. New York, McGraw-Hill.

Sánchez, L. A., \& Martínez-González, Y. (2014): "Propuesta de un nuevo enfoque para evaluar la peligrosidad por inundaciones pluviales", Tecnología y Ciencias del Agua, 5, 6, pp. 53-67.

Sánchez-Román, L. A. (2012): “Inundaciones pluviales en una cuenca urbana aplicando el método de ponderación mixta", Ingeniería Hidráulica y Ambiental, 13, 2, pp. 90-105.

Sevillano-Rodríguez, M. E., \& Bravo-Peña, L. C. (2018): “Análisis multitemporal de la expansión física en la ciudad de Santiago de Cali, Colombia”, DECUMANOS, 3, 3, pp. 28-43.

Sevillano-Rodríguez, M. E., Bravo, L. C., Alatorre, L. C., \& Salcedo, E. d. (2020): "Identificación de zonas de inundación a partir de imágenes (SAR) y de eventos históricos de inundación: caso de estudio Santiago de Cali, Colombia”. Cuadernos Geográficos, 59, 2, pp. 308-329.

Shale-Ogato, G., Bantider, A., Abebe, K., \& Geneletti, D. (2020): "Geographic information system (GIS)-Based multicriteria analysis of flooding hazard and risk in Ambo Town and its watershed, West shoa zone, Oromia regional State, Ethiopia”, Journal of Hydrology: Regional Studies, 27, pp. $1-18$.

Shever, S., Haase, D., \& Meyer, V. (2011): "Exploring multicriteria flood vulnerability by integrating economic, social and ecological dimensions of flood risk and coping capacity: From a starting point view towards an end point view of vulnerability", Natural Hazards, 58, 2, pp. 731751.

Shivaprasad-Sharma, S. V., Parth-Sarathi, R., Chakravarthi, V., \& Srinivasa- Rao, G. (2018): "Flood risk assessment using multi-criteria analysis: a case study from Kopili River Basin, Assam, India", Geomatics, Natural Hazards and Risk, 9, 1, pp. 79-93.

Siddayao, G. P., Valdez, S. E., \& Fernández, P. L. (2014): “Analytic hierarchy process (AHP) in spatial modeling for floodplain risk assessment", International Journal of Machine Learning and Computing, 4, 5, pp. 450-457. 


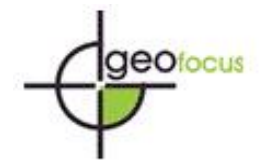

Sevillano Rodríguez, M. E. (2020): "Zonificación de la amenaza ante inundaciones a partir de un método de evaluación multicriterio en la ciudad de Santiago de Cali, Colombia", GeoFocus, n ${ }^{\circ}$ 25, p. 47-76. http://dx.doi.org/10.21138/GF.661

Soza-Zamora, D. Z. (2018): Tutorial: Procesamiento datos DEM Alos-1 PalSAR RTC. Disponible en $\quad$ https://es.scribd.com/document/392931606/Tutorial-Procesamiento-Datos-DEM-Alos-1PalSAR-RTC (Consultado 10-01-2019).

Uribe-Alcántara, E. M., Montes-León, M. A., \& García-Celis, E. (2010): "Mapa nacional de índice de inundación", Tecnología y Ciencias del Agua, pp. 73-85.

Vásquez, E. (1990): "Historia del desarrollo económico y urbano en Cali”, Boletín socioeconómico, 20, pp. 2-28.

Wilchex-Chaux, G. (1993): "La vulnerabilidad global", en: Mascrey, A. (Ed.): Los desastres no son naturales. Bogotá, LA RED, pp. 1-140.

Wong, P. (2010): “Ordenamiento ecológico y ordenamiento territorial: retos para la gestión del desarrollo regional sustentable en el siglo XXI", Estudios sociales, 1, pp. 10-39.

Yahaya, S., Ahmad, N., \& R.F.Abdalla. (2010): "Multicriteria analysis for flood vulnerable areas in Hadejia-Jama' are River Basin, Nigeria", European Journal of Scientific Research, 42, pp. 71-83. 